This is the peer reviewed version of the following article: [L. Yao; A. Rahmanudin; N. Guijarro; K. Sivula : Organic Semiconductor Based Devices for Solar Water Splitting. Advanced Energy Materials. 2018-11-15. DOI : 10.1002/aenm.201802585.], which has been published in final form at [http://dx.doi.org/10.1002/aenm.201802585]. This article may be used for non-commercial purposes in accordance with Wiley Terms and Conditions for Self-Archiving.

\title{
Organic semiconductor based devices for solar water splitting
}

\section{Liang Yao, Aiman Rahmanudin, Néstor Guijarro, and Kevin Sivula*}

Dr. L. Yao, Dr. A. Rahmanudin, Dr. N. Guijarro, Prof. K. Sivula

Laboratory for Molecular Engineering of Optoelectronic Nanomaterials, École Polytechnique Fédérale de Lausanne (EPFL), Station 6, 1015 Lausanne, Switzerland.

E-mail: kevin.sivula@epfl.ch

Keywords: solar fuel, hydrogen evolution reaction, conjugated polymers, photoelectrochemistry, tandem cell

Solution processable organic semiconductors are well-established as high-performance materials for inexpensive and scalable solar energy conversion in organic photovoltaic (OPV) devices, but their promise in the economic conversion of solar energy into chemical energy (solar fuels) has only recently been recognized. Herein, the main approaches employing organic semiconductor-based devices towards solar $\mathrm{H}_{2}$ generation via water splitting are compared and performance demonstrations are reviewed. OPV-biased water electrolysis is seen to advance significantly with the development of the tandem OPV device and the optimization of operating potential and redox catalysts. This approach now exceeds $6 \%$ solarto-hydrogen conversion efficiency while over $10 \%$ is reasonably feasible. In contrast, while the direct water splitting by an organic semiconductor in a photoelectrochemical cell has attractive advantages, increasing the performance remains a challenge. Photocathodes employing a bulk-heterojunction have been optimized to give $7-8 \mathrm{~mA} \mathrm{~cm}{ }^{-2}$ water reduction photocurrent under standard conditions, but photoanodes remain $<1 \mathrm{~mA} \mathrm{~cm}{ }^{-2}$, and robustness remains a critical issue. However, recent investigations into the direct organic semiconductor/electrolyte interface have brought important insights into free charge generation, the nature of the semiconductor/catalyst interface, and the stability of organic photoelectrodes. Outlooks toward advancing both approaches are discussed.

\section{Introduction}

In a sustainable energy economy, based entirely on renewable and carbon neutral energy sources, the conversion of Solar irradiance to electricity by photovoltaic devices is foreseen to represent a principal technology. ${ }^{[1,2]}$ However, due to the diurnal and annual variations of insolation, meteorological phenomena, and its global non-uniformity, methods to store solar energy at various magnitudes and over several timescales will be needed. ${ }^{[3]}$ The conversion of Solar energy into the chemical energy of molecular bonds (Solar fuels) is a promising 
approach for long-term storage on a global scale, and can also provide various industries with fundamental chemical feedstocks to replace fossil fuels sources. Water electrolysis, which effectively transforms electrical energy into molecular hydrogen $\left(\mathrm{H}_{2}\right)$ and oxygen $\left(\mathrm{O}_{2}\right)$ that can be reconverted into electrical energy on demand with a fuel cell, represents a leading approach for the scalable long-term storage and transport of renewable energy, ${ }^{[4]}$ given the terrestrial abundance of $\mathrm{H}_{2} \mathrm{O}$. Considering that $\mathrm{H}_{2}$ is also an essential chemical building block (e.g. for $\mathrm{NH}_{3}$ production) and can also be converted into liquid fuels with $\mathrm{CO}_{2}$ using industrially established transformations (reverse water-gas shift and Fischer-Tropsch), an energy and chemical economy based primarily on hydrogen produced from Solar energy is not only conceivable, but highly anticipated. However, to attain economically-feasible solardriven $\mathrm{H}_{2}$ production at a global scale, challenges remain in the identification of materials and systems that can achieve high Solar-to-fuel energy conversion efficiency and robust performance at low-cost. ${ }^{[5]}$ In particular, the development of suitable light harvesting semiconducting materials with ideal properties for solar-driven water splitting has been a major focus of research in the past decades. ${ }^{[6]}$ To date, although numerous inorganic semiconductors $^{[7-12]}$ have demonstrated solar water-splitting in various device architectures, ${ }^{[13]}$ systems that can produce $\mathrm{H}_{2}$ at a price competitive with fossil fuel based $\mathrm{H}_{2}$ production remain elusive. ${ }^{[14]}$ Therefore, a new generation of high performance, stable materials based on earth abundant elements and low cost processing is needed to enable solar water splitting for the globalized storage of solar energy and a carbon-neutral industrial chemical economy.

Solution-processed organic semiconductors, which contain an aromatic core of conjugated carbon-carbon bonds, which brings an electronic structure suitable for semiconducting operation, and flexible appendages (e.g. alkyl groups) to afford solubility in common solvents, represent a promising class of materials to enable low-cost, high performance Solar fuel production. Indeed, both conjugated polymers and small molecules have already been well- 
established in organic photovoltaic (OPV) devices. ${ }^{[15-20]}$ The solar-to-electricity (photovoltaic) power conversion efficiency $\left(\eta_{\mathrm{PV}}\right)$ of state-of-the art OPVs has surpassed 17\% by optimization of the organic semiconductor molecular structures and device engineering. ${ }^{\text {[21- }}$ ${ }^{24]}$ Considering the success of solution-processable organic semiconductors in OPV, research is now emerging to exploit their advantages over inorganic semiconductors in Solar-tohydrogen conversion. In particular, organic semiconductors (OSs) consist of earth abundant elements, and their optical bandgap, energy levels, charge transport mobility and other physical properties can be customized by molecular engineering, ${ }^{[17]}$ which affords the possibility of tuning their properties for ideal operation in solar water splitting devices. Moreover, OS devices can be prepared from low cost and large scale processing techniques, such as doctor blading, ${ }^{[25,26]}$ inkjet printing, ${ }^{[27,28]}$ and roll-to-roll printing. ${ }^{[29,30]}$ Hence, solar water splitting devices based on solution-processed OSs can potentially meet the requirements for large-scale implementation of this technology. Herein, we present an overview of the application of OS-based devices in solar driven water splitting focusing on two main strategies: OPV-biased water electrolysis and OS-based photoelectrochemical (PEC) cells. The opportunities and challenges of these strategies are discussed and contrasted to competing technologies using organic light harvesting systems for solar-driven water splitting including dye-sensitized inorganic photoelectrodes ${ }^{[31-34]}$ and photocatalytic ${ }^{[35-37]}$ systems with an aim to promote the further development of OSs in the field of solar driven fuel production.

\section{Device architectures for solar-driven water splitting with organic semiconductors}

When it comes to the design of semiconductor-based devices for solar-driven water splitting, different configurations have been proposed and tested. ${ }^{[13]}$ An obvious choice is the use of a standard photovoltaic device electrically connected to an electrochemical cell in a "PV-biased electrosynthetic cell” configuration. In a typical OPV device, a bulk-heterojunction (BHJ) between electron donor and acceptor phases separated at the nanometer-scale is used as the 
photoactive layer. Upon light absorption, excitons generated in both phases are split at the donor:acceptor interface generating free charge carriers (electrons and holes) that are separately transported throughout the blend and eventually collected at the selective contacts. Here, the voltage generated under illumination corresponds to the difference in the chemical potential of the two photogenerated charge carriers. As the standard Gibbs free energy $\left(\Delta \mathrm{G}^{\circ}\right)$ for splitting water into hydrogen and oxygen is $237 \mathrm{~kJ} \mathrm{~mol}^{-1}$, in principle a photopotential equivalent to the standard electrode potential $\left(\Delta \mathrm{E}^{\circ}\right)$ of $1.23 \mathrm{~V}$ would be the minimum required to drive the overall water splitting reaction. However, an operation voltage in the range of 1.5 $-1.9 \mathrm{~V}$ is typically needed due to kinetic overpotential losses and electrical resistance. Indeed, the voltage required is dictated by the magnitude of the electrical current and chemical species involved in the electrocatalysis. Although OPV devices have greatly advanced in the last few decades including the optimization of photopotential, ${ }^{[38,39]}$ the reported highest open circuit photovoltage of a single junction OPV is still much lower than $1.4 \mathrm{~V}$, therefore a single junction OPV could not be used to drive overall water-splitting without an externally-applied bias. While standard BHJ OPV cells can certainly be simply connected in series to increase the potential to be sufficient for water electrolysis, ${ }^{[40,41]}$ a tandem OPV cell configuration, where two or more series-connected BHJs are layered on a single substrate, can also be used to increase the photopotential. Moreover, the optoelectronic tunability of the BHJ and its components makes OPVs ideally suitable for tandem cell fabrication, ${ }^{[42,43]}$ and the tandem structure benefits from an intrinsic advantage of superior scalability compared to single junction cells. ${ }^{[44]}$ Therefore efforts to couple OPVs to electrolysis cells have mostly focused on the implementation of these multijunction tandem cells. Figure 1a shows the device architecture of a tandem OPV-biased water splitting cell, which consists of an OPV device wired to an electrolysis cell filled with aqueous electrolyte. The cathode performs the hydrogen evolution reaction (HER) and the anode performs the oxygen evolution reaction (OER). From an electron energy point of view, such a device operates as shown in Figure $1 b$. 
In this case two BHJ sub-cells are shown connected in series by an intermediate contact layer (ICL) where photogenerated electrons from one BHJ recombine with photogenerated holes from the other. Due to the series connection of the BHJ sub-cells in a tandem OPV cell, the maximum photopotential (the open circuit potential, $\mathrm{V}_{\mathrm{oc}}$ ) produced by the tandem cell is equal to the sum of the $\mathrm{V}_{\text {oc's }}$ from each BHJ sub-cell, in the absence of voltage loss at the intermediate contact layers. ${ }^{[43]}$ If the photopotential produced by the tandem cell is greater than the $1.23 \mathrm{~V}$ required to split water plus the resistive and kinetic overpotentials, the two water splitting half reactions (OER and HER) will occur in the electrochemical cell. Importantly, the overpotential losses can be reduced by employing optimized HER and OER catalysts on the electrodes. Since the OPV-biased water splitting consists of two separated modules, viz. the PV cell and electrolyzer, both can be optimized independently facilitating the optimization of the complete device. In addition, since this approach does not require the OPV cells to contact the aqueous electrolyte, the OPV device can be easily protected by encapsulation, which is beneficial for long term stability. As a drawback, using tandem OPVs requires elaborate device fabrication using orthogonal solvent processing and multiple ultrathin layers without pinholes, which increases the cost and complexity of the tandem OPV cells with respect to single junction counterparts. Despite this possible disadvantage, the performance of OPV-biased water splitting has advanced significantly in recent years, as detailed in Section 3.

An alternative approach for solar-driven water splitting using OS-based devices is to use photoelectrodes in a PEC cell (Figure 2a) where the (hole or electron) extraction layers or the OS itself is in direct contact with the aqueous electrolyte. Both single component OS (e.g. a conjugated polymer or a molecular semiconductor thin film) and donor:acceptor BHJs (e.g. conjugated polymer:fullerene composites) can be applied as photoactive layers in OS-based PEC cells as indicated schematically in Figure $2 b$. The electronic operation of a PEC cell based on a photocathode or a photoanode wired to a non-light absorbing counter electrode is 
shown in Figure 2c and 2d, respectively. Here, either an OER or HER catalyst can be integrated directly onto the photoelectrode to reduce the overpotential, but since neither a single OS nor a BHJ can supply the required photopotential of $>1.23 \mathrm{~V}$, an externally-applied bias, $\mathrm{V}_{\mathrm{app}}$, is generally required to drive the overall water splitting reaction. As photoelectrodes are typically examined in a 3-electrode configuration with a potentiostat, the applied voltage is usually reported as potential relative to a reference (e.g. the reversible hydrogen electrode, RHE).

Following this idea of a direct OS-liquid junction, unassisted overall solar water splitting can be achieved without an external bias, in principle, using a photoanode/photocathode tandem cell, where the photoelectrodes harvest complementary portions of the solar spectrum and together generate sufficient photopotential. ${ }^{[4]}$ This type of PEC tandem cell for solar-tohydrogen conversion has been considered to have advantages over the PV plus electrolyzer approach in part due to the conceivable simplicity of the PEC approach, ${ }^{[14,46]}$ which requires only a few materials to integrate the light-absorbing and electrocatalysis functions. In addition, since the electrochemical reactions occur directly at the semiconductor/liquid interfaces, the current densities passing through the materials under PEC operation are about two orders of magnitude smaller than those in commercial electrolyzer systems $\left(10-20 \mathrm{~mA} \mathrm{~cm}^{-2}\right.$ vs. $1000-$ $2000 \mathrm{~mA} \mathrm{~cm}^{-2}$ ). This greatly reduces the demands on the HER and OER catalysts and represents a route to reduce losses due to overpotentials and electrical resistance. ${ }^{[47]}$ Nevertheless, the development of OS-based PEC tandem cells for overall water splitting has remained a challenge, and the single photoelectrode PEC cell architecture, shown in Figure 2, has been primarily used to date. This single photoelectrode cell is a convenient platform for examining the performance of OS-based photoelectrodes under the relatively challenging PEC operation conditions. Indeed, since a photoelectrode integrates multiple physical process including light absorption, free charge generation, charge transport and charge transfer to the electrolyte at the solid/liquid interface, it needs to satisfy key requirements. First, as the 
photoelectrode is in direct contact with the aqueous electrolyte, the OS materials used should exhibit stability under the operating conditions, either via protecting overlayers or intrinsic stability. Secondly, the OSs should have optimized energy band gap energy $\left(E_{\mathrm{g}}\right)$ to balance solar energy utilization and the development of photopotential. In addition, the HOMO and LUMO levels of the OSs should be appropriately aligned with the water redox levels $\left(E_{\mathrm{H}+/ \mathrm{H} 2}\right.$ and $\left.E_{\mathrm{H} 2 \mathrm{O} / \mathrm{O} 2}\right)$ in the electrolyte used to establish a thermodynamic driving force for the photoreduction or photooxidation reactions. Besides this, a favorable charge mobility is preferable in the OS thin film in order to decrease the charge recombination during transport. Much progress toward engineering OS-based photoelectrodes to satisfy the above requirements has been recently reported and will be presented in Section 4.

A related approach to the OS PEC cell is to use a photoelectrode consisting of a molecular dye (metal-complex or conjugated organic) grafted to a high surface area wide band-gap inorganic oxide scaffold in the dye sensitized photoelectrochemical (DS-PEC) cell approach, ${ }^{[48]}$ which operates analogous to the dye-sensitized photovoltaic cell. ${ }^{[49]}$ Conceptually the main difference of the DS-PEC approach compared to using a BHJ active layer in a PEC device is the decoupling of light absorption and charge transport in the DSPEC. As a drawback only a few wide band-gap oxides have suitable optoelectronic properties. ${ }^{[50]}$ This limits the choice of dye to those with energy levels suitable for charge carrier injection into the oxide. Moreover, the high temperature processing conditions required to form high performance oxide layers makes large-area roll-to-roll processing a complex challenge. ${ }^{[51]}$ Regardless, the DS-PEC approach have proven invaluable to enable the study and engineering of the complex physical processes occurring in photoelectrochemical cells (e.g. charge transfer from dye to catalysts and recombination with carriers in the oxide). Accordingly, this approach is under active development by many groups and recent reviews dedicated to the DS-PEC approach have been published. ${ }^{[32,52,53]}$ 
A final technique to afford light-induced hydrogen production using carbon-based organic semiconductors is to simply disperse or dissolve the organic semiconductor directly in water to drive the direct photocatalytic hydrogen production. Insoluble micron or nanometer sized particles can be used in a heterogeneous fashion, or soluble molecular dyes (metal-complex or conjugated organics) can be employed in a homogeneous photocatalysis approach. From a technoeconomic viewpoint, solar hydrogen production via photocatalytic dispersions has a significant cost advantage over the PV plus electrolysis or the PEC approach-if similar material performance can be achieved-given the simplicity of the photocatalytic approach. ${ }^{[54]}$ However, the performance of semiconducting materials in photocatalytic water splitting lags far behind that of the PEC approach despite both techniques employing a direct semiconductor/liquid junction. ${ }^{[55,56]}$ This is in part due to the difficulty to efficiently separate photogenerated carriers (preventing recombination) and the inherent fragility of molecular photocatalysts. Despite this, the photocatalytic approach is technologically enticing and organic semiconductor photocatalysts both in heterogeneous and homogeneous systems have drawn considerable research attention in recent years. Since the challenges of developing efficient photocatalytic systems differ from the PV-biased and the PEC water splitting approach, and the progress in organic semiconductor photocatalysis has been recently reviewed $^{[35-37,57-59]}$ it will not be the focus of this report. In the next sections we will review and discuss the main results in the emerging fields of OPV-biased water electrolysis and OSbased photoelectrochemical (PEC) cells.

\section{OPV-biased solar water splitting systems}

\subsection{Side-by-side series-connected systems}

The straightforward method of series-connecting single junction OPV cells to afford sufficient photovoltage to split water was first reported in 2011 by Aoki et al. ${ }^{[40]}$ where six standard poly(3-hexylthiophene) (P3HT) : [6,6]-phenyl $\mathrm{C}_{61}$ butyric acid methyl ester $\left(\mathrm{PC}_{61} \mathrm{BM}\right) \mathrm{BHJ}$ 
cells positioned side-by-side were connected in series to generate an $\mathrm{V}_{\text {oc }}$ of $2.9 \mathrm{~V}$. Connected to two Pt electrodes as cathode and anode the operating current density, $\mathrm{J}_{\mathrm{op}}$, and operating voltage, $\mathrm{V}_{\mathrm{op}}$, for electrolysis in $0.1 \mathrm{M} \mathrm{H}_{2} \mathrm{SO}_{4}$ electrolyte was $1.3 \mathrm{~mA} \mathrm{~cm}{ }^{-2}$ and $2.6 \mathrm{~V}$, respectively, under standard ( 1 sun) illumination conditions corresponding to a solar-tohydrogen conversion efficiency, $\eta_{\mathrm{STH}}$, of $1.6 \%$. We note that the $\mathrm{V}_{\mathrm{op}}$ of $2.6 \mathrm{~V}$ is much greater than the 1.5-1.9 $\mathrm{V}$ typically required. This high voltage demand originates from the large overpotential for water splitting in this case. Indeed, although Pt is well-known for being an excellent HER catalyst, its performance as OER catalyst is poor, thus inducing a high overpotential on the anode.

The concept of series-connected side-by-side single junction OPV-biased solar water splitting was extended in 2016 by Esiner et al. who theoretically examined the performance limits of this approach considering state-of-the-art OPV materials and catalysts. ${ }^{[60]}$ The authors predicted a maximum $\eta_{\text {STH }}$ of $6.9 \%$ with three series connected cells, and further demonstrated a step toward this limit with OPVs based on a donor of Poly[4,8-bis(5-(2ethylhexyl)thiophen-2-yl)benzo[1,2-b;4,5-b']dithiophene-2,6-diyl-alt-(4-(2-ethylhexyl)-3fluorothieno[3,4-b]thiophene-)-2-carboxylate-2-6-diyl)] (coded as PTB7-Th) and $\mathrm{PC}_{71} \mathrm{BM}$ as the acceptor using a Pt cathode and a $\mathrm{RuO}_{2}$ OER catalyst on a $\mathrm{Ti}$ anode. With three series connected OPVs they obtained a $\eta_{\mathrm{STH}}$ of $6.1 \%$ (with $\mathrm{J}_{\mathrm{op}}=4.95 \mathrm{~mA} \mathrm{~cm}{ }^{-2}$ and $\mathrm{V}_{\mathrm{op}}=1.5 \mathrm{~V}$ ). Interestingly, aside from a study on side-by-side single junction devices in their work, the authors predicted values of $\eta_{\mathrm{STH}}$ around $10.0 \%$ when employing vertically stacked (tandem) photoactive layers. The predicted improvement in the multi-junction tandem case was ascribed to more efficient photon harvesting and reduced losses, suggesting this as a path forward.

\subsection{Tandem OPV-biased systems}

In practice multi-junction tandem OPV cells have indeed excelled in OPV-biased solar hydrogen production given the recent advances in the development of OPV tandem 
cells, ${ }^{[19,21,61-63]}$ which have achieved solar-to-electricity (photovoltaic) power conversion efficiencies $\left(\eta_{\mathrm{PV}}\right)$ exceeding $17 \%$ and $\mathrm{V}_{\mathrm{oc}}>1.6 \mathrm{~V} \cdot{ }^{[24]}$ In 2013 , Janssen and co-workers first demonstrated solar-driven water splitting using a triple junction tandem OPV cell with one junction based on a BHJ with a wide bandgap polymer (coded PF10TBT) and $\mathrm{PC}_{61} \mathrm{BM}$ together with two junctions based on a small band gap polymer (coded PDPPTPT) and $\mathrm{PC}_{61} \mathrm{BM}$ (see polymer chemical structures in Figure 3a and the device schematic in Figure $3 b) .{ }^{[64]}$ The authors engineered the intermediate contacts as a multilayer $\mathrm{ZnO} / \mathrm{pH}$-neutral poly(3,4-ethylenedioxythiophene):poly(styrenesulfonate) (PEDOT:PSS)/Nafion structure to optimize the charge transport and transparency, and the triple junction tandem OPV cell exhibited a $\eta_{\mathrm{PV}}$ of $5.3 \%$, an impressive $\mathrm{V}_{\mathrm{oc}}$ of $2.33 \mathrm{~V}$, and a voltage at the maximum power point of $1.7 \mathrm{~V}$ (see I-V curve in Figure 3c). Solar water splitting biased by this tandem OPV device was realized in $1 \mathrm{M} \mathrm{KOH}$ electrolyte using Pt for both cathode and anode (Figure 3c, inset), and a maximum $\eta_{\text {STH }}$ of $3.1 \%$ was obtained. The same group improved upon this result by tuning the $\mathrm{BHJ}$ active layer components and employing $\mathrm{RuO}_{2}$ as the HER and OER catalyst to give a $\eta_{\text {STH }}$ of $5.4 \% .{ }^{[65]}$ Earth abundant $\mathrm{NiMoZn}$ and $\mathrm{Co}_{3} \mathrm{O}_{4}$ HER and OER catalysts, respectively, were also employed to deliver a $\eta_{\mathrm{STH}}$ of $4.9 \% .^{[65]}$

Homo-tandem OPV cells, which integrate multiple junctions containing the same BHJ composition, can also be adopted as a strategy to provide a sufficient voltage for water splitting. It has been shown that homo-tandem solar cells can not only improve light harvesting, but also reduce bimolecular recombination by decreasing the carrier transport distance. ${ }^{[63,66]}$ As a result, the $\eta_{\mathrm{PV}}$ of the homo-tandem solar cells under optimal conditions is higher than that of single BHJ OPV. A two-BHJ junction tandem cell can provide a reasonable trade-off between device complexity and increased performance, if the tandem can be optimized to produce sufficient photovoltage. Beaujuge and co-workers optimized a homotandem solar cell for OPV-driven water splitting using 2x PBDTTPD:PC ${ }_{71} B M$ photoactive layers (see donor polymer structure Figure 4a) and $\mathrm{MoO}_{3}$ /ultrathin $\mathrm{Al} / \mathrm{ZnO}$ as an ICL (Figure 
4b). ${ }^{[67]} \mathrm{A} \eta_{\mathrm{PV}}$ of $8.35 \%$ (9\% greater than the single $\mathrm{BHJ}$ control) and a $\mathrm{V}_{\mathrm{oc}}$ of $1.84 \mathrm{~V}$ were obtained (see Figure $4 \mathrm{c}$ for the $\eta_{\mathrm{PV}}-\mathrm{V}$ curve). Solar-driven water splitting was carried out at $\mathrm{V}_{\mathrm{op}}=1.5 \mathrm{~V}$ with $\mathrm{Pt}$ and nickel foam as cathode and anode, respectively, in $1 \mathrm{M} \mathrm{NaOH}$ and a maximum $\eta_{\text {STH }}$ of $6.1 \%$ was achieved (see red curve in Figure $4 \mathrm{c}$ ). The authors also showed that a triple junction homo-tandem would not increase the water splitting performance as the $\mathrm{V}_{\text {op }}$ of the electrolysis cell $(1.5 \mathrm{~V})$ was already close to the maximum power point of the double-junction cell as can be seen in Figure 4c. In a similar demonstration, Esiner et al. developed a homo-tandem cell with a $\eta_{\mathrm{PV}}$ of $5.3 \%$ and a $\mathrm{V}_{\mathrm{oc}}$ of $1.74 \mathrm{~V}$ that was based on $2 \mathrm{x}$ BHJs of PTPTIBDT-OD:PC ${ }_{71} \mathrm{BM}$ (see polymer structure Figure 4a) and a $\mathrm{ZnO} / \mathrm{pH}-$ neutral PEDOT:PSS/MoO 3 multilayer ICL. ${ }^{[68]}$ The PTPTIBDT-OD was optimized to have a higher $E_{\mathrm{g}}(2.04 \mathrm{eV})$ and thus produce more photovoltage, but since only $1.5 \mathrm{~V}$ was required when using $\mathrm{RuO}_{2}$ as both OER and HER catalyst in $1 \mathrm{M} \mathrm{KOH}$, and a lower current was produced (3.5 $\mathrm{mA} \mathrm{cm}^{-2}$ during water splitting), the $\eta_{\mathrm{STH}}$ was limited to $4.3 \%$.

The water splitting operating voltage of ca. $1.5 \mathrm{~V}$ reported for the examples above with optimized catalysts were accomplished in either strongly acidic or alkaline electrolytes. Indeed, in order to minimize the overpotentials, PV-biased water splitting is generally carried out at $\mathrm{pH} 0$ or 14 . However, these harsh conditions can lead to a strong electrode and cell corrosion. Elias et al. addressed this drawback and demonstrated a $\eta_{\mathrm{STH}}$ of $6 \%$ in $\mathrm{pH}-$ neutral electrolyte by using a homo-tandem solar cell (see device structure Figure 4d). ${ }^{[69]}$ To overcome the higher operating voltage required, the tandem solar cell employed $3 \mathrm{x}$ BHJs based on PTB7:PCBM and optimized ICLs of $\mathrm{MoO}_{3} /$ ultrathin-Ag/PFN (a polyfluorene derivative), and showed a $\eta_{\mathrm{PV}}$ of $8.7 \%$, a $\mathrm{V}_{\mathrm{oc}}$ of $2.1 \mathrm{~V}$, and a remarkably high FF of $76 \%$ (see Figure 4e). A graphic carbon $(\mathrm{GC}) / \mathrm{RuO}_{2}$ cathode and stainless steel (SST)/NiMoZn anode were used to drive electrolysis at $\mathrm{V}_{\mathrm{OP}}=1.70-1.75 \mathrm{~V}$ (green line Figure 4e). More importantly, $79 \%$ of the operation current remained after 50 hours of photo-driven electrolysis (Figure 4f), indicating a promising stability. 


\subsection{Outlook on OPV-biased solar water splitting}

The progress achieved in the development of OPV-biased water splitting is summarized by the device performance metrics presented in Table 1. Although significant advances have been achieved over the first demonstration with side-by-side P3HT based cells, the reported highest $\eta_{\text {STH }}$ of about $6 \%$ is still inferior to state-of-the-art results based obtained at 1 sun illumination with inorganic group III-V triple tandem junction cells $\left(\eta_{\mathrm{STH}}=16.3 \%{ }^{[70]}\right)$, two side-by-side halide perovskite cells $\left(12.3 \%{ }^{[71]}\right)$ or three side-by-side $\mathrm{CuIn}_{\mathrm{x}} \mathrm{Ga}_{1-\mathrm{x}} \mathrm{Se}_{2}$ cells $\left(10 \%{ }^{[72]}\right)$. The $\eta_{\text {STH }}$ in the state-of-the-art OPV-biased approach is mainly limited by the output current density of the OPV assembly and the electrolysis $\mathrm{V}_{\mathrm{op}}$ range of 1.5-1.7 V. So far, for OPV-biased water splitting the highest reported $J_{\mathrm{op}}$ is less than $6 \mathrm{~mA} \mathrm{~cm}^{-2}$. In principle, the short circuit current density $\left(\mathrm{J}_{\mathrm{sc}}\right)$ of a series-connected tandem solar cell is determined by the lowest current density obtained from its sub-cells. Thus, one strategy to improve the $\mathrm{J}_{\mathrm{sc}}$ of a tandem OPV device, and thus to improve $\mathrm{J}_{\mathrm{op}}$ for water splitting, is to more effectively match the $\mathrm{J}_{\mathrm{sc}}$ of the sub-cells. In addition, the development of high performance non-fullerene acceptors has significantly advanced $\eta_{\mathrm{PV}}$ in OPV cells in the last few years. ${ }^{[62,73]}$ In general these optimized non-fullerene acceptors exhibit a strong light absorption, tunable $E_{\mathrm{g}}$, a favorable charge mobility, and the ability to decrease photopotential losses. ${ }^{[20,74]}$ Recently, dual BHJ tandem OPV cells have reached $\eta_{\mathrm{PV}}$ over $17 \%$ using near-infrared non-fullerene acceptors optimized transport layers, and optimized light absorption. ${ }^{[22,24]}$ The champion cell to date has shown a $\mathrm{J}_{\mathrm{sc}}$ of over $10 \mathrm{~mA} \mathrm{~cm}^{-2}$ at $1.5 \mathrm{~V}$, thus tandem OPV - biased water splitting can certainly surpass a $\eta_{\mathrm{STH}}$ of $10 \%$ in the near future. Regarding the possible industrial implementation of OPV-biased hydrogen production, assuming the stability issues of OPV can be successfully addressed, ${ }^{[75]}$ the tandem cell configuration has the advantage over the side-by-side approach by providing an improved scalability for OPV device fabrication. However, the scalability of the overall OPV-biased electrolysis systems will also have to be considered. Simply scaling up the OPV active area while keeping the same 
electrode area will mean higher electrolysis current density and thus higher operating voltages will be required. This would in turn require tandem OPVs with higher voltage at the maximum power point then the current state-of-the-art. Alternatively the active area of the electrodes could also be increased, however, this requires redesigning the electrolysis system and expensive metals like Pt and Ru should be replaced by earth-abundant electrocatalysts.

\section{Direct water splitting from organic semiconductor PEC cells}

While the performance of OPV-driven solar hydrogen production is not far behind the performance of solar water splitting with other thin film PV-driven approaches, the relative complexity of the tandem architectures required to achieve the highest device performance poses a serious drawback towards the large-scale implementation of this technology. As was mentioned in Section 2, the integration of the semiconductor and the electrode in a photoelectrochemical cell can bring potential advantages toward overall solar-to-hydrogen conversion devices. However, engineering robust and high-performance OS-based photoelectrodes with a direct interface between the semiconducting material and the aqueous electrolyte brings additional challenges. Recent work on developing OS-based photocathodes for water reduction and photoanodes for water oxidation have begun to address these challenges establishing the foundations to develop feasible solar fuel production with organic semiconductors in PEC cells.

\subsection{Photocathodes using a single organic semiconductor}

In a characteristic inorganic semiconductor photocathode for solar water reduction, the equilibration of electron energy at the semiconductor/liquid junction induces a space-charge region in the semiconductor wherein the associated electric field serves to separate photogenerated electrons in the conduction band from holes in the valence band. Given the formation of excitons instead of free charges in OS materials under ambient operation and the need to employ a donor-acceptor heterojunction for generating free charges, employing organic photocathodes with some form of organic/organic heterojunction is of interest (see 
Section 4.2). However, a few reports have investigated PEC water reduction by a single OS. In fact, this configuration can be an effective platform to study the complex interactions between an OS and a liquid electrolyte. Early work by Holcroft and coworkers on photocathodes of solution-processed regiorandom or regioregular P3HT used electrochemical impedance spectroscopy to establish that a space-charge region does form at the semiconductor/aqueous electrolyte interface. ${ }^{[76,77]}$ Regioregular P3HT performed better as a photocathode with a photocurrent density, $\mathrm{J}_{\mathrm{ph}}$, of $20 \mu \mathrm{A} \mathrm{cm} \mathrm{cm}^{-2}$ under 1 sun illumination at $-0.14 \mathrm{~V}$ vs RHE in $0.1 \mathrm{M} \mathrm{H}_{2} \mathrm{SO}_{4} \mathrm{pH} 1$ (compared to $\sim 1 \mu \mathrm{A} \mathrm{cm}^{-2}$ with regiorandom P3HT). The photocurrents were stable and no degradation of the polymer was observed after hours of irradiation, suggesting the photocurrent was due to the reduction of a solution species and not due to the irreversible photoelectrochemical reduction of the film. Since $\mathrm{O}_{2}$ was excluded from the PEC cell, the authors concluded that the most reasonable explanation for the origin of photocurrent was the reduction of protons and the evolution of hydrogen (although no $\mathrm{H}_{2}$ was detected). ${ }^{[77]}$ The authors conjectured that a protonated P3HT at the polymer-electrolyte interface is an intermediate in the $\mathrm{H}_{2}$ evolution reaction. However it should be noted residual $\mathrm{Ni}$ in $\mathrm{P} \mathrm{HT}^{[78]}$ (as a nickel catalyst was used to prepare the polymer) was likely present as well and could participate as electrocatalyst for HER.

To achieve enhanced mechanical attachment of the OS to the inorganic electrode substrate for photocathode application, conjugated polymers in the polythiophene family, such as poly(2,2'-bithiophene) (PBTh) or polyterthiophene (PTTh), have been polymerized directly onto the electrode (without including solubilizing side chains). For example, $\mathrm{Ng}$ and coworkers employed a vapor phase polymerization method to prepare PBTh films in the presence of $\mathrm{Fe}(\mathrm{III}) \mathrm{p}$-toluene sulphonate as oxidant. ${ }^{[79]}$ Increasing the roughness of the film was found to be important for increasing the photocurrent, suggesting that either exciton dissociation was occurring at the semiconductor/liquid junction, or that the HER reaction limited electron transfer. Under 1.6-sun illumination in $1 \mathrm{M}$ phosphate buffer ( $\mathrm{pH} 7)$ a 
photocurrent of ca. $100 \mu \mathrm{A} \mathrm{cm} \mathrm{cm}^{-2}$ was obtained at $0.11 \mathrm{~V}$ vs RHE, and ca. $50 \%$ of the photocurrent remained after 12 days of continuous testing. ${ }^{[80]}$ Molecular $\mathrm{H}_{2}$ evolution was observed by GC analysis at an average Faradic efficiency of $72 \%$. Winther-Jensen and coworkers recently extended this work by demonstrating an iodine-vapor-assisted polymerization in the absence of metals to fabricate PTTh films (see Figure 5a for synthesis scheme). ${ }^{[81]}$ XPS data indicated no detectable iodine or other metals in the resulting PTTh films after a washing step, and the resulting film was slightly porous according to the SEM image (Figure 5b). The PTTh photocathode showed an increased photocurrent density and a more positive photocurrent onset potential with increasing $\mathrm{pH}$ electrolyte solution (Figure 5c). This non-Nernstian behavior was attributed to the oxidation state of the PTTh insofar as it must reach a state close to neutral to be photoactive. The authors further leveraged this result to reduce the potential needed to drive overall water splitting in a two-electrode water electrolysis cell with a PTTh photocathode and a (dark) $\mathrm{MnO}_{\mathrm{x}}$ anode. At a low applied bias potential $\mathrm{V}_{\mathrm{app}}=0.3 \mathrm{~V}$ in $\mathrm{pH} 12$ electrolyte water splitting with a Faradic efficiency of $91 \%$ was observed with a current density of ca. $1 \mu \mathrm{A} \mathrm{cm} \mathrm{cm}^{-2}$. At $\mathrm{V}_{\text {app }}=1.23 \mathrm{~V}$ the current density increased to $25 \mu \mathrm{A} \mathrm{cm}^{-2}$ and reasonably stable photocurrent for $30 \mathrm{~min}$ was shown (See Figure 5d).

In addition to engineering the mechanical robustness of the OS film by directly polymerizing to the substrate, a parallel research theme has been the development of OS materials with increased surface area for solar water splitting applications. Indeed, if free charges are generated at the semiconductor/electrolyte interface, then maximizing this surface area could serve to increase the photocurrent even without a traditional donor:acceptor type heterojunction. In this regard porous semiconducting network polymers, including carbon nitrides ${ }^{[82,83]}$ covalent triazine frameworks, ${ }^{[84,85]}$ conjugated microporous polymers, ${ }^{[86,87]}$ and covalent organic frameworks (COFs), ${ }^{[88,89]}$ have been of recent interest for application as dispersed particle photocatalysts or water splitting, and a few review articles have 
summarized their recent progress — as mentioned in Section $2 .{ }^{[35,37]}$ Considering the promising performance of these materials as particle photocatalysts for $\mathrm{H}_{2}$ evolution from water, it can be expected that photocathodes based on these materials could also operate with high conversion efficiency. However, a factor limiting investigations into the photoelectrochemistry of porous semiconducting network polymers is photoelectrode preparation itself. Indeed, the network structure of these materials leads to a poor solubility and challenges with processing into thin films. However, recently Bein's group reported a photocathode based on an organic porous polymer coded BDT-ETTA (see chemical structure Figure 6a). ${ }^{[90]}$ The BDT-ETTA COF film was synthesized on an ITO substrate (Figure 6b) using a chemical bath method, where the orientation of the COF film could be controlled by the synthesis solvent. Mesitylene or anisole led to a non-oriented film growth, while a mesitylene-dioxane mixture resulted in an oriented and porous COF film. PEC tests indicated the non-oriented films was neither photoactive nor stable under operation conditions (comparing the dark and light cyclic voltammetry, CV, curves in Figure 6c do not evidence photoactivity). In contrast, a stable photoresponse $\left(\mathrm{J}_{\mathrm{ph}}\right.$ of ca. $1 \mu \mathrm{A} \mathrm{cm} \mathrm{cm}^{-2}$ at $0.3 \mathrm{~V}$ vs RHE in in nitrogen-purged $0.1 \mathrm{M} \mathrm{Na}_{2} \mathrm{SO}_{4}$ ) was obtained for the oriented films even in the absence of cocatalyst (Figure 6c). A four-fold increase in $\mathrm{J}_{\mathrm{ph}}$ (up to $4.3 \mu \mathrm{A} \mathrm{cm} \mathrm{cm}^{-2}$ at $0.3 \mathrm{~V}$ vs RHE) was achieved after loading Pt nanoparticles as HER catalyst (Figure 6d), and the photocurrent even in the absence of Pt was stable for at least 5 hours (Figure 6e). In the case of the stability measurements for bare electrodes shown in Figure 6e, the authors positioned a Pt mesh near the photocathode to oxidize the products of the photocathode. The oxidation current (Figure $6 e$, red curve) coincided with the photocurrent from the cathode, strongly suggesting that that the bare BDT-ETTA COF can photoelectrochemically reduce water to $\mathrm{H}_{2}$. While this result represents the first application of porous organic semiconducting network polymer as a water splitting photoelectrode, the reported photocurrent still limits the practical application. From the view of device engineering, the authors stated that improvement is likely possible by 
reducing the energy mismatch between the work function of ITO $(-4.7 \mathrm{eV})$ and the HOMO level of BDT-COF film $(-5.5 \mathrm{eV})$. In addition, improved control over film formation may be possible using an in situ film polymerization technique for semiconducting network polymers. ${ }^{[91]}$

Overall, despite the relatively low photocurrent density observed in the single-semiconductor photocathode systems, the use of only one OS has helped to gain insight into the operation of the organic semiconductor/aqueous electrolyte interface. Indeed, the results suggest that free charge generation can occur at the semiconductor electrolyte interface, and that bare unmodified organic semiconductors can drive the HER reaction, albeit at low efficiency. This later point accords with recent results using organic photocatalyst particle dispersions for $\mathrm{H}_{2}$ evolution from water as well. ${ }^{[86]}$ However, the exact mechanism for water reduction on organic semiconductors is still an open question, and the role of metal impurities ${ }^{[87]}$ cannot be easily discounted.

\subsection{Donor:acceptor heterojunction photocathodes}

While single OS photocathodes provide an interesting platform for gaining insight into the OS-electrolyte interface, poor charge separation apparently limits their performance, since even with HER catalysts, photocurrent densities are well below $1 \mathrm{~mA} \mathrm{~cm}{ }^{-2}$. Employing donor:acceptor heterojunction photocathodes have accordingly been investigated to produce higher photocurrents, although significant photoelectrode engineering has been required. Early work by Abe et al. in the 2000s demonstrated the potential of organic heterojunctions as photocathodes in aqueous solution. ${ }^{[92,93]}$ Vapor-deposited bilayers of a metal-free phthalocyanine and $\mathrm{C}_{60}$ were investigated for their ability to reduce $\mathrm{Fe}^{3+}$ to $\mathrm{Fe}^{2+}$ and $\mathrm{J}_{\mathrm{ph}}$ on the order of $10 \mu \mathrm{A} \mathrm{cm} \mathrm{cm}^{-2}$ was observed. This work pointed to a kinetic limitation of electron transfer at the $\mathrm{C}_{60} /$ electrolyte interface. In 2012, Lanzarini et al. extended the concept of heterojunction organic photocathodes to solution-processed BHJs by employing P3HT:PCBM in direct contact with an aqueous saline solution from which $\mathrm{J}_{\mathrm{ph}}<1 \mu \mathrm{A} \mathrm{cm}{ }^{-2}$ was reported. ${ }^{[94]}$ 
Interestingly, gas bubbles were observed on the illuminated portion of the photocathode during operation, suggesting the production of $\mathrm{H}_{2}$ gas, although this was not quantified. Soon after, Bourgeteau and co-workers introduced an earth abundant HER catalyst $\mathrm{MoS}_{3}$ on top of a P3HT:PCBM BHJ layer. ${ }^{[95]}$ The $\mathrm{J}_{\mathrm{ph}}$ was improved to $200 \mu \mathrm{A} \mathrm{cm}^{-2}$ at $0 \mathrm{~V}$ vs RHE, and $\mathrm{H}_{2}$ production was confirmed by gas chromatography. These initial results indicated that a hybrid organic semiconductor $\mathrm{BHJ} /$ inorganic catalyst device structure could integrate the exciton dissociation and catalytic activity to exploit photogenerated free charge transfer at electrode/electrolyte interface. Nevertheless, the $\mathrm{J}_{\mathrm{ph}}$ generated was significantly lower than the $\mathbf{J}_{\mathrm{sc}}$ (normally larger than $8 \mathrm{~mA} \mathrm{~cm}{ }^{-2}$ ) of OPV cell based on P3HT:PCBM. ${ }^{[96]}$

Interface engineering is currently emerging as a promising route to improve the performance of P3HT:PCBM based photocathodes. Indeed, in OPV cells, well-designed interface layers are able to remarkably improve the device performance as the interface layer plays a crucial role on the charge extraction and mitigating interfacial recombination. ${ }^{[97,98]}$ For a photocathode an ideal hole transport layer (HTL) must possess suitable energy levels to accept photogenerated holes from the $\mathrm{BHJ}$ donor $\mathrm{HOMO}$ and block photogenerated electrons from the acceptor LUMO, while energy levels of an ideal electron transport layer (ETL) must accept electrons and transfer these electrons to the HER co-catalyst, but also block photogenerated holes. In addition, ideal interfacial transport layers should possess sufficient carrier mobility and a low light absorption. Examples of HTLs and ETLs that have been investigated for application in P3HT:PCBM based photocathodes are given in Figure 7a, which shows the material conduction band edge (LUMO) and valence band edge (HOMO) energy levels with respect to vacuum energy and the potential of normal hydrogen electrode $(\mathrm{NHE}=\mathrm{RHE}$ at $\mathrm{pH}$ 0). Especially important for PEC operation, sufficient robustness and water resistance are also required, even for a HTL inserted between the conductive substrate and the BHJ in a photocathode. This was demonstrated by Bourgeteau et al. when they compared well known PEDOT:PSS, the most commonly used HTL in OPV devices to 
reduced graphene oxide $(\mathrm{rGO}), \mathrm{NiO}_{\mathrm{x}}$, and $\mathrm{MoO}_{\mathrm{x}}$ layers. ${ }^{[99]}$ The linear scanning voltammetry (LSV) curves of the photocathodes based on ITO/HTL/P3HT:PCBM/MoS 3 are shown in Figure 7b-e. Note that the LSVs are collected under intermittent illumination showing both the dark current and the reductive photocurrent.

The photocathode with PEDOT:PSS as an HTL provided a photocurrent of less than $100 \mu \mathrm{A}$ $\mathrm{cm}^{-2}$ at $0 \mathrm{~V}$ vs. RHE. In comparison, a photocurrent of at least $1 \mathrm{~mA} \mathrm{~cm}^{-2}$ was obtained in the photocathodes based on $\mathrm{rGO}, \mathrm{NiO}_{\mathrm{x}}$, and $\mathrm{MoO}_{\mathrm{x}}$. This difference can be attributed to the interaction of water and the PEDOT:PSS. Moreover, it should be noted that among the better performing HTLs in that work, $\mathrm{MoO}_{\mathrm{x}}$, exhibited the most positive photocurrent onset potential and also the highest photocurrent density, $\mathrm{J}_{\mathrm{ph}}$, of about $2.5 \mathrm{~mA} \mathrm{~cm}{ }^{-2}$ at $0 \mathrm{~V}$ vs RHE. These results demonstrate the feasibility of improving the photoelectrode performance by changing the interface layer, and suggests that the other factors besides just the conduction and valence band edges could be important for optimizing performance. Indeed, subsequent works have investigated a variety of HTL materials, including cross-linked PEDOT:PSS, ${ }^{[100]}$ nanoflake $\mathrm{MoS}_{2},{ }^{[101]} \mathrm{CuI},{ }^{[102]} \mathrm{MoO}_{3} \cdot{ }^{[103]}$

Compared to HTLs, the development of materials for the ETL is less advanced. Although $\mathrm{C}_{60}$ and $\mathrm{Al}: \mathrm{ZnO}(\mathrm{AZO})$ as ETLs demonstrated some improvement in the performance $\mathrm{BHJ}$ photocathodes, the photocurrent was observed to quickly decay due to the instability of $\mathrm{C}_{60}$ and AZO in acid water. ${ }^{[104,105]}$ In contrast, given its excellent aqueous stability, large bandgap energy, and effective ability for electron transport, the most effective ETL material so far demonstrated is titanium oxide. Importantly, the conduction band of $\mathrm{TiO}_{2}$ also matches well with the LUMO level of most acceptors in the typical BHJ (see Figure 7a), which is beneficial for electron extraction, and its low valence band level can effectively block photogenerated holes from transferring across the semiconductor liquid junction, reducing interfacial recombination. However, depositing high quality $\mathrm{TiO}_{2}$ on top of an organic $\mathrm{BHJ}$ can be a challenge, given the high temperatures requisite for synthesis. Haro and co-workers overcame 
this challenge by using a sol-gel solution-based approach with annealing at only $85^{\circ} \mathrm{C}$ to make $\mathrm{TiO}_{\mathrm{x}}$ overlayers ${ }^{[100]}$ and demonstrated the importance of the layer thickness in photocathodes with geometry shown in Figure 8a (note here that the Pt layer HER co-catalyst deposited by sputtering is about $0.5 \mathrm{~nm}$ thick). While photocathodes with only $40 \mathrm{~nm}$ of $\mathrm{TiO}_{\mathrm{x}}$ lost about half of their photocurrent after $60 \mathrm{~min}$ (Figure 8b), a $140 \mathrm{~nm} \mathrm{TiO}_{\mathrm{x}}$ layer gave a $\mathrm{BHJ}$ photocathode with $>3$ hours of stable operation under intermittent illumination with chronoamperometry, CA, measurements at $0 \mathrm{~V}$ vs RHE (Figure 8c). Alternatively, Steier and co-workers developed a novel low temperature atomic layer deposition (ALD) to prepare $\mathrm{TiO}_{2}$ on a $\mathrm{BHJ}$, and a $\mathrm{J}_{\mathrm{ph}}$ of $>3 \mathrm{~mA} \mathrm{~cm}^{-2}$ at $0 \mathrm{~V}$ vs RHE and a stability of $>3 \mathrm{~h}$ under CA measurements were also achieved. ${ }^{[102]}$ ALD-grown $\mathrm{TiO}_{\mathrm{x}}$ ETLs have also been shown to stabilize photocathodes based on a BHJ of PCDTBT (see Table 1 for full polymer name) and PCBM. In this case Francàs et al. used a NiO HTL and $\mathrm{RuO}_{2}$ nanoparticle HER co-catalyst in the optimized photocathode structure. Interestingly, both the $\mathrm{NiO} \mathrm{HTL}$ and the $\mathrm{TiO}_{\mathrm{x}} \mathrm{ETL}$ were shown to be necessary to maintain stable photocurrents (of ca. $3 \mathrm{~mA} \mathrm{~cm}^{-2}$ at $0 \mathrm{~V}$ vs RHE in $0.1 \mathrm{M}$ phosphate buffer, $\mathrm{pH} 7$ ) for $>5 \mathrm{~h} .{ }^{[106]}$

Using the $\mathrm{TiO}_{2}$ ETL plus Pt HER co-catalyst strategy while optimizing the HTL led to a breakthrough in the photocurrent of BHJ photocathodes when CuI was employed by Di Fonzo, Antognazza, and co-workers. After first using $\mathrm{MoO}_{3}$ as an $\mathrm{HTL},{ }^{[103]}$ they switched to $\mathrm{CuI}$ and demonstrated a photocathode (FTO/CuI/P3HT:PCBM/TiO $2 / \mathrm{Pt})$ with a $\mathrm{J}_{\text {ph }}$ of $>7 \mathrm{~mA} \mathrm{~cm}{ }^{-2}$ at 0 $\mathrm{V}$ vs RHE (in $0.1 \mathrm{M} \mathrm{H}_{2} \mathrm{SO}_{4}$ plus $0.1 \mathrm{M} \mathrm{Na}_{2} \mathrm{SO}_{4}$ at $\mathrm{pH}$ 1.0) and a remarkable photocurrent onset potential of around $0.6 \mathrm{~V}$ vs RHE. ${ }^{[107]}$ The photoelectrode cross-sectional image and LSV are shown in Figure 9a and Figure 9b, respectively. It should be noted that similar photocurrent density (> $7 \mathrm{~mA} \mathrm{~cm}^{-2}$ at $0 \mathrm{~V}$ vs RHE in $0.5 \mathrm{M} \mathrm{H}_{2} \mathrm{SO}_{4}$ ) was also obtained by optimizing interlayers as reported by Bourgeteau et al. ${ }^{[105]}$ who employed an Al/Ti metallic layer between the ETL $(\mathrm{LiF})$ and the HER catalyst $\left(\mathrm{MoS}_{3}\right)$ in an ITO/PEDOT:PSS/P3HT:PCBM/LiF/Al/Ti- $\mathrm{MoS}_{3}$ device structure. While these works 
represent the benchmark $\mathrm{J}_{\mathrm{ph}}$ of $7-8 \mathrm{~mA} \mathrm{~cm}{ }^{-2}$ for a BHJ based photocathode for solar $\mathrm{H}_{2}$ production, the stability of the photocathode still remains a critical performance limitation. In the case of Di Fonzo and Antognazza's work the authors observed a ca. 75\% reduction of photocurrent after $1 \mathrm{~h}$ operation (CA at $0 \mathrm{~V}$ vs RHE). The delamination of the $\mathrm{Pt}$ from the $\mathrm{TiO}_{2}$ ETL (See Figure 9c) was cited as a major factor in the poor stability. The authors improved on the stability by spin coating a branched polyethyleneimine (PEI) overlayer from a $0.1 \mathrm{wt} \%$ in ethanol solution onto the Pt given "its good adhesion and coating properties, hydrophilicity, proton affinity, and chelating properties on both ions and metals." ${ }^{[107]}$ Without affecting the initial $J_{\mathrm{ph}}$ or the onset potential, the PEI layer resulted in an increase in stability (only about $57 \%$ of the $\mathrm{J}_{\mathrm{ph}}$ was lost after 1 hour), but a significant decrease was still observed (see Figure 9d). In the case of Bourgeteau et al., ${ }^{[105]}$ the photocathode with a LiF/Al/Ti interfacial layer was found to lose $45 \%$ of the initial photocurrent over only 10 min (CA at 0 $\mathrm{V}$ vs RHE). The use of titanium as the sole interfacial layer increased the stability under operation, with a loss of $12 \%$ under similar conditions. Despite the drawback of stability, these demonstrations have confirmed the possibility of obtaining values of photocurrent density and onset potentials that rival traditional inorganic p-type photocathodes. Indeed, the favorable onset potential and high $\mathrm{J}_{\mathrm{ph}}$ observed in the optimized configuration reported by Di Fonzo, Antognazza and coworkers leads to a single electrode (not tandem cell) applied bias photon-to-current efficiency $\left(\mathrm{ABPE}^{[108]}\right)$ of ca. $3.7 \%$ at the maximum power point $(\mathrm{mpp}=0.3$ V vs RHE, see inset of Figure 9b).

In particular, a highly positive photocurrent onset potential is an important photocathode property for the construction of tandem PEC cells and this result has paved the way towards more practical device demonstrations using organic semiconductor photocathodes. For example, Shao et al. reported a tandem PEC cell for bias free overall water splitting, using a Pt coated P3HT:PCBM photocathode and a modified $\mathrm{TiO}_{2}$ (with $\mathrm{IrO}_{2}$ as the OER) photoanode, that gave an operating photocurrent density of ca. $150 \mu \mathrm{A} \mathrm{cm}{ }^{-2}$, which 
corresponds to an $\eta_{\mathrm{STH}}=0.2 \%{ }^{[109]}$ In addition, Abe et al. examined a water-splitting system comprising a $\mathrm{TiO}_{2}$ photoanode and a ITO/Zinc phthalocyanine/ $\mathrm{C}_{60}-\mathrm{Pt}$ photocathode where overall (2-electrode) water splitting occurred at a small applied bias voltage of $0.25 \mathrm{~V}$ with an $\eta_{\mathrm{STH}}=0.1 \%{ }^{[110]}$ Another engineering aspect towards the practical application of organic semiconductor photocathodes is to develop low-cost processing techniques by avoiding vacuum deposition steps for under- or over-layers. Two recent reports demonstrated allsolution-processed photocathodes based on P3HT:PCBM BHJs from which $\mathrm{J}_{\text {ph }}$ of $5.25 \mathrm{~mA}$ $\mathrm{cm}^{-2}$ and $6.01 \mathrm{~mA} \mathrm{~cm}^{-2}$ at $0 \mathrm{~V}$ vs RHE were obtained, respectively. ${ }^{[111,112]}$ To further establish the scalability of the solution-processing fabrication approach, Bellani et al. prepared a photocathode with an area of $9 \mathrm{~cm}^{2}$ on a flexible substrate and a photocurrent of $2.8 \mathrm{~mA} \mathrm{~cm}{ }^{-2}$ at $0 \mathrm{~V}$ vs RHE was observed. ${ }^{[112]}$ Overall these demonstrations strongly show that organic semiconductors can perform as competitive photocathodes, exhibiting not only high photocurrents and onset potentials, but also providing advantages toward low cost scalable PEC cells.

\subsection{Organic semiconductor based photoanodes}

In contrast to the significant progress of photocathodes, OS-based water splitting photoanodes are still at an early stage of development. This is partly due to the complexities of the water oxidation reaction, which requires four holes to generate oxygen and has been established to be a kinetic bottleneck of water splitting. ${ }^{[2,113]}$ Furthermore, organic materials generally exhibit poor stability in strongly basic electrolytes in which photoanodes normally obtain better performance. So far, the best performance of a non-inorganic-based photoanode was achieved from dye sensitized photoanode $\left(\mathrm{J}_{\mathrm{ph}}=1.7 \mathrm{~mA} \mathrm{~cm}{ }^{-2}\right.$ at $0.6 \mathrm{~V}$ vs RHE in a pH 6.8 phosphate buffer solution using a molecular Ru-based sensitizer). ${ }^{[114]}$ However, since the development of the DS-PEC approach ${ }^{[53]}$ differs significantly from using a single organic semiconductor or a BHJ as photoactive layer as discussed in Section 2, progress in this field will not be discussed further in this review. Instead, photoanodes using OSs as the primary 
light harvester and charge transport medium offer some advantage over the DS-PEC and are under parallel development. For example, in 2006 Abe, Nagai and coworkers reported a bilayer with 3,4,9,10-perylenetetracarboxylic acid bisbenzimidazole (PTCBI, an n-type semiconductor) and cobalt(II) phthalocyanine (CoPc). Photocurrents of about $20 \mu \mathrm{A} \mathrm{cm} \mathrm{cm}^{-2}$ at 1.2 V vs RHE were observed (in aqueous $\mathrm{NaOH}$ solution $\mathrm{pH} 11$ ) and $\mathrm{O}_{2}$ was measured. ${ }^{[115]} \mathrm{In}$ this case the CoPc was thought to play a role of light absorption/charge separation (accepting holes from the PTCBI and also injecting electrons into it) while also activating the OER via the hole-doped $\mathrm{Co}^{\mathrm{III}} \mathrm{Pc}$ centers. In another example, 3,4,9,10-perylenetetracarboxylic dianhydride (PTCDA) was combined with PCBM in a photoanode and its PEC characteristics under various conditions were studied. ${ }^{[116]}$ More recently, Finke and coworkers continued efforts with perylene-based OSs using N,N'-bis(phosphonomethyl)-3,4,9,10-perylenediimide (PMPDI) with a $\mathrm{CoO}_{\mathrm{x}}$ OER catalyst to obtain a respectable $\mathrm{J}_{\mathrm{ph}}$ of $150 \mu \mathrm{A} \mathrm{cm}^{-2}$ (at $1.56 \mathrm{~V}$ vs RHE in $0.1 \mathrm{M} \mathrm{pH} 7 \mathrm{KPi}$ buffer). ${ }^{[117]}$ Interestingly, in this study the authors argued that the generation of free charges from exciton dissociation occurred at the semiconductor/substrate (ITO) interface and not the semiconductor/liquid interface. Despite the detection of $\mathrm{O}_{2}$ with an estimated Faradaic efficiency of $85 \pm 15 \%$, the photocurrent decreased rapidly-losing more than half of its initial $\mathbf{J}_{\mathrm{ph}}$ in the first 5 min of CA testing.

Stability is indeed a major issue with OS-based photoanodes, and accordingly innovative materials and approaches have been pursued to attain both high OER photocurrent and reasonable longevity in organic semiconductor-based photoanodes. For example, Wang et al. demonstrated that an ultra-thin $\mathrm{ZnO}$ over-layer (deposited by $\mathrm{ALD}$ at $85^{\circ} \mathrm{C}$ ) on a $\mathrm{PC}_{71} \mathrm{BM}$ thin film could both improve the photocurrent magnitude and the photoanode stability. ${ }^{[118]}$ This is somewhat surprising as the energy band alignment of the PCBM/ZnO interface (shown schematically in Figure 10a) suggests that photogenerated holes in the organic semiconductor should be blocked by the $\mathrm{ZnO}$ over-layer. The dependence of the measured water oxidation photocurrent on the thickness of the $\mathrm{ZnO}$ over-layer (Figure 10b), which first increases and 
then decreases after a certain limit $(\sim 1.3 \mathrm{~nm})$, suggests that photogenerated holes are able to tunnel from the PCBM to the $\mathrm{ZnO} /$ electrolyte interface to participate in the OER. Furthermore, the increase the $\mathrm{J}_{\mathrm{ph}}$ for $\mathrm{ZnO}$ thicknesses less than $1.3 \mathrm{~nm}$ implies that the $\mathrm{ZnO}$ layer affords increased charge separation or charge injection until the layer is too thick for tunneling. Moreover, CA results (Figure 10c) show that a $1.44 \mathrm{~nm} \mathrm{ZnO}$ overlayer extends the half-life for the photocurrent generation from $200 \mathrm{~s}$ in the bare photoanode to over $1000 \mathrm{~s}$. The authors of this work also optimized the semiconductor/substrate interface (also with $\mathrm{ZnO}$ ) and obtained a $\mathrm{J}_{\mathrm{ph}}$ of up to $60 \mu \mathrm{A} \mathrm{cm} \mathrm{cm}^{-2}$ at $1.23 \mathrm{~V}$ vs RHE. ${ }^{[118]}$

A strategy alternative to protecting the semiconductor with overlayers could be to simply identify an organic semiconductor with an intrinsic stability under the harsh water oxidation conditions. Bornoz et al. ${ }^{[119]}$ investigated this possibility using an exceptionally robust semiconducting polymer, poly(benzimidazobenzophenanthroline) coded as BBL (chemical structure Figure 11a inset), as a photoanode for water oxidation. BBL had been previously characterized as an exceptionally thermally stable organic semiconductor with reasonable electron mobility up to $0.1 \mathrm{~cm}^{2} \mathrm{~V} \mathrm{~s}^{-1} \cdot{ }^{[120,121]}$ However, given the absence of solubilizing side chains and the ridged ladder-type structure, the processing of this polymer into thin films has posed a significant challenge. Two processing strategies (dip coating and dispersion spray deposition) were investigated to prepare thin film photoanodes of BBL. The PEC response of these electrodes in a sacrificial hole acceptor electrolyte $\left(0.5 \mathrm{M} \mathrm{Na}_{2} \mathrm{SO}_{3}, \mathrm{pH} 7\right)$ displayed significantly different $\mathrm{J}_{\mathrm{ph}}$ under intermittent 1 sun illumination depending on the processing route (See Figure 11a). The higher photocurrent of the spray-deposited photoanode $(150 \mu \mathrm{A}$ $\mathrm{cm}^{-2}$ at $1.23 \mathrm{~V}$ vs RHE), was not attributed to a greater light absorption (similar optical density is seen in both types of photoanode in Figure 11d) but rather the morphology of the BBL film was argued to be the main cause for the difference. Indeed, the dip coated thin-film displayed a relatively smooth morphology (Figure 11b), while in contrast the spray coated electrode exhibited a rougher nanofiber morphology (Figure 11c) with an increased 
BBL/electrolyte interfacial area. Since the oxidation of the sulfite should not be kinetically limiting, increased free charge generation due to exciton dissociation at the semiconductor/electrolyte interface was reasoned to be the origin of the difference in this case (in contrast to free charge generation at the semiconductor/substrate interface). The bare BBL photoanodes also showed photoactivity in non-sacrificial electrolyte (sulfate/phosphate buffer pH 7) reaching $J_{\mathrm{ph}} \sim 30 \mu \mathrm{A} \mathrm{cm}{ }^{-2}$ at $1.23 \mathrm{~V}$ vs RHE with the spray-coated film (Figure 11e). Remarkably, CA measurement (Figure 11e inset) showed a stabilized $\mathrm{J}_{\mathrm{ph}} \sim 8 \mu \mathrm{A} \mathrm{cm}{ }^{-2}$ for 30 min after an initial decrease. In addition, similar to the PTTh photocathode discussed in Section 4.1, a non-Nerstian behavior of the photocurrent was observed with $\mathrm{pH}$, with more basic electrolyte giving higher steady-state photocurrents (up to $27 \mu \mathrm{A} \mathrm{cm} \mathrm{cm}^{-2}$ at $\mathrm{pH} 12$ ). Interestingly the steady-state photocurrent was not attributed to molecular $\mathrm{O}_{2}$ evolution but rather $\bullet \mathrm{OH}$ was detected, indicating that the bare $\mathrm{BBL}$ cannot drive the catalytically-complex OER. More importantly, no indication of the self-oxidation of BBL after a 2-hour PEC test was detected, suggesting that BBL is sufficiently robust for application as a photoanode. After loading a Ni-Co catalyst on the BBL photoanode, gas chromatography confirmed molecular $\mathrm{O}_{2}$ production with a Faradaic efficiency of $82 \pm 16 \%$. This demonstration gives tangible prospect to the possibility of stable OS-based photoanodes, however the photocurrent remains far below what would be needed for practical application.

Indeed, the magnitude of the photocurrents observed with all of the OS-based photoanode discussed above are small compared to the progress reported on organic semiconductor photocathodes. However, and despite the poor performance, these initial works as discussed above have not only established that the nanostructure of the film plays a crucial role on the performance and indicates strategies for increasing the stability, but also have opened a new path for the rational design and optimization of photoanodes based on organic semiconductors.

\subsection{Outlook on organic photoelectrodes}


The performance metrics of the key reports of OS-based photocathodes and photoanodes are summarized in Table 2. Overall the application of a BHJ and engineering ETLs HTLs and HER catalysts have demonstrated that OS-based photocathodes have a promising application potential in low-cost and scalable PEC cells. Nonetheless, compared to the state-of-art inorganic photocathodes, which have achieved a photocurrents of $10-35 \mathrm{~mA} \mathrm{~cm}^{-2}$ at $0 \mathrm{~V}$ vs RHE after four decades development (e.g. $10 \mathrm{~mA} \mathrm{~cm}{ }^{-2}$ from $\mathrm{CuO}_{2},{ }^{[122,123]} 35 \mathrm{~mA} \mathrm{~cm}{ }^{-2}$ from InP, ${ }^{[124]} 25 \mathrm{~mA} \mathrm{~cm}^{-2}$ from $\mathrm{WSe}_{2},{ }^{[125]}$ and $13 \mathrm{~mA} \mathrm{~cm}^{-2}$ from $\mathrm{CuInS}_{2}{ }^{[126]}$ ), the performance of organic BHJ photocathodes remain inferior. However, the fabrication of these highperformance inorganic HER photocathodes is based on expensive and non-scalable processing techniques, such as atomic layer deposition, sputtering, and thermal evaporation. Indeed, while the innovative synthesis of these competing inorganic photocathodes via low cost methods has attracted considerable attention in recent years, ${ }^{[127-130]}$ the obtained photocurrent is comparable to that of the BHJ photocathode reported by Bourgeteau et al. ${ }^{[105]}$ and Comas Rojas et al. ${ }^{[107]}$ Thus combining the aspects of photocurrent and low-cost implementation, OS-based photocathodes are on an equal position to their inorganic counterparts. In addition, the ability to tune the band-gap and the energy levels of the organic semiconductor gives advantages to control the light absorption and the photocurrent onset potential, as was recently demonstrated using subnaphthalocyanine and sexithiophene small molecule semiconductors. ${ }^{[131]}$ Currently, the main limitation of organic BHJ photocathodes lies in photocurrent instability. The photocurrent decay, in part, can result from the interface layer degradation and catalyst detachment. Some strategies, such as adopting robust interface layers such as GO, ${ }^{[112]}$ adding a protective PEI layer on the top of catalyst, ${ }^{[107]}$ and blending Nafion polymer in the catalyst, ${ }^{[12]}$ have exhibited the ability to suppress the photocurrent decay to some extent. Nevertheless, BHJ photocathodes with photocurrent densities above 5 $\mathrm{mA} \mathrm{cm} \mathrm{cm}^{-2}$ and even modest stability (less than $10 \%$ photocurrent decay after 1 hour under operation) under standard testing conditions remain elusive in the field. Therefore, continued 
efforts on preventing catalyst detachment and searching for robust interface layers are still required. On the other hand, irreversible chemical and morphological degradation of organic BHJ could also be one of the reasons for photocurrent decay. Unexpected chemical reactions could occur for organic materials under light illumination in the presence of and water and $\mathrm{O}_{2 .}{ }^{[132]}$ Since various organic BHJs that are more stable than P3HT:PCBM are developed in recent years, ${ }^{[133,134]}$ investigation into the relationship between the photocurrent stability and molecular structures of the OS used in BHJ based photocathodes should follow to establish the criteria for stability in BHJ photocathode materials.

Regarding the outlook on OS-based photoanode development, a first task should be to demonstrate higher water-oxidizing photocurrent densities, as to-date the performance lags far behind that exhibited by state-of-the-art photocathodes. Taking inspiration from the photocathodes, the use of BHJ photoanode could be one effective strategy to improve the free charge generation. However, the HOMO level position of the electron donor material needs to be carefully considered for application in water oxidation. As shown in Figure 7 a, the $\mathrm{O}_{2} / \mathrm{H}_{2} \mathrm{O}$ redox potential $\left(E_{\mathrm{H} 2 \mathrm{O} / \mathrm{O} 2}\right)$ lies at $1.23 \mathrm{~V}$ vs $\mathrm{NHE}(\mathrm{pH} 0)$, corresponding to a vacuum electron energy of $-5.67 \mathrm{eV}$, and the Nernstian shift of the redox potential $59 \mathrm{mV}$ for every decade of pH effectively shifts the potential "up" with respect to the vacuum energy with increasing the $\mathrm{pH}$ of electrolyte solution. Considering the observed non-Nernstian behavior of organic semiconductor photoelectrodes, increasing the $\mathrm{pH}$ of the working solution could be beneficial, affording a higher driving force for OER. For example, $E_{\mathrm{H} 2 \mathrm{O} / \mathrm{O} 2}$ at $\mathrm{pH} 7$ is equivalent to an electron energy of $-5.26 \mathrm{eV}$ vs. Vacuum (or $-5.02 \mathrm{eV}$ at $\mathrm{pH} 11$ ). However, to avoid degradation of the organic semiconductors in strongly basic electrolytes and also drive the OER (where an overpotential of $0.3 \mathrm{~V}$ is typically needed for $10 \mathrm{~mA} \mathrm{~cm}^{-2}$ ) a HOMO level of at least $-5.3 \mathrm{eV}$ will likely be needed for the stable and high-performance operation of a direct BHJ/electrolyte based photoanode. This may be possible with some of the more recently developed Quinoxaline ${ }^{[135]}$ or Benzodithiophene ${ }^{[16]}$ based donor polymers. The successful 
demonstration of a BHJ photoanode with $\mathrm{J}_{\mathrm{ph}} \sim 10 \mathrm{~mA} \mathrm{~cm}{ }^{-2}$ will open the door for the construction of $\mathrm{BHJ}$ photocathode/BHJ photoanode tandem cells ${ }^{[45,136]}$ for overall water splitting.

A final point for investigation for both photoanodes and photocathodes is the rational design of the interface with the respective redox catalyst. Indeed, reports to date have mostly considered depositing an inorganic catalyst on the surface of the OS. This organic/inorganic interface can lead to high charge transfer resistance and suffers from poor mechanical stability. Developing a molecular understanding of this interface or even by implementing stable molecularly-grafted catalyst complexes at the OS-electrolyte interface will play a pivotal role in advancing the performance of OS-based photoelectrodes for solar water splitting application.

\section{Summary and Conclusions}

This report has summarized the application of organic semiconductors in thin-film-based devices for solar-driven water splitting. Various device configurations have been demonstrated, from simply using OPV cells to bias an electrolyzer, to directly immersing an OS-based photoelectrode into an aqueous electrolyte. In the past few years, both OPV-biased water splitting and OS-based photoelectrodes have drawn considerable research interest and displayed a rapid development. For OPV-biased water splitting, the use of tandem structures has proven advantageous over a simple side-by-side approach to deliver the photopotential required to split water in $\mathrm{H}_{2}$ and $\mathrm{O}_{2}$. The highest $\eta_{S T H}$ efficiency has improved from just $1.6 \%$ in 2011 to now exceeding 6\% with a remarkable stability (current density $>75 \%$ retained after $50 \mathrm{~h}$ illumination). Optimizing the tandem OPV device structure, HTL, ETL, and the HER and OER catalysts has proven a fruitful method to advance performance. The main limitation of the $\eta_{\mathrm{STH}}$ is attributed to the low $\mathrm{J}_{\mathrm{op}}$ at the voltage required (1.4-1.6 V). However, recent optimization of OPV tandem cells via the combination of novel polymers, non-fullerene 
acceptors, tuned film thicknesses and interfacial layers, the $\eta_{P V}$ of tandem OPVs has advanced past $17 \%$, which brings new opportunities to the development of OPV-biased water splitting. Thus, $\eta_{\text {STH }}$ from OPV-biased water splitting will reasonably surpass $10 \%$ in the near future. In addition, considering the economic competitiveness of OPV-biased solar fuel generation, while the solution-processed nature of the state-of-the-art devices are a great advantage, the continued development of earth abundant and inexpensive catalysts for the HER and OER electrodes will be needed. With a $10 \% \eta_{\mathrm{STH}}$, a system with an inexpensive fabrication costs and stability on the order of 10 years, the OPV-biased generation of solar fuel will be a realistic contender compared to their inorganic PV counterparts. Considering OS-based PEC cells, which have some potential advantages over the OPV-biased approach, work on single OS-based thin film photoelectrodes has given important insights into the complex behavior of the OS/aqueous electrolyte interface. The photoelectrode morphology has been shown to be important, suggesting that free charge generation can occur at the OS/electrolyte junction. Moreover, the non-Nernstian behavior of this interface has proven useful-upon optimization of the electrolyte $\mathrm{pH}$ - to improve the driving force for free charge transfer. However, the $\mathrm{J}_{\mathrm{ph}}$ of single-OS photoelectrodes has remained low. The use of a BHJ together with optimized interface layers and catalysts has proven constructive in enhancing $J_{\mathrm{ph}}$, which for photocathodes have increased from $<1 \mu \mathrm{A} \mathrm{cm}^{-2}$ in 2012 to over $7-8 \mathrm{~mA} \mathrm{~cm}^{-2}$ to date. The development of OS-based photoanodes falls far behind, partly due to a lack of materials with energy levels suitable for driving the OER in mild conditions. BHJs based on a donor OS with a deep HOMO level should be explored to advance the performance. In addition to advancing the $\mathrm{J}_{\mathrm{ph}}$ and photocurrent onset potential in OS-based photoelectrodes, the challenge of improving the photocurrent stability remains a critical issue. As pointed out above, a few factors might contribute to the observed photocurrent decay, including catalyst detachment, interface layer degradation, and even chemical or morphological transformation of the OS materials. While using robust interfacial layers and protection strategies for catalysts can 
improve the robustness, a stability beyond hundreds of minutes remains a challenge. In order to achieve long term stability over the duration required for practical application, deep insights between the organic materials and photocurrent degradation mechanisms are still required. Overall, the examples reviewed in this report show that carbon-based semiconductors exhibit promising potential in solar-driven $\mathrm{H}_{2}$ production via water splitting. After substantial continued efforts, it is optimistic that organic semiconductors - with their advantages of great natural abundance, optoelectronic tunability, and low cost processingwill become one of the most competitive classes of materials for solar driven water splitting.

\section{Acknowledgements}

We thank the Swiss Competence Centre for Energy Research (SCCER Heat and Electricity Storage, contract \#CTI 1155002545) and the European Research Commission (ERC starting grant "CEMOS" Project 336506) for financial support. N. G. acknowledges an SNSF Ambizione Energy grant (PZENP2_166871).

Received: ((will be filled in by the editorial staff))

Revised: ((will be filled in by the editorial staff)) Published online: ((will be filled in by the editorial staff))

\section{References}

[1] F. Creutzig, P. Agoston, J. C. Goldschmidt, G. Luderer, G. Nemet, R. C. Pietzcker, Nat. Energy 2017, 2, 17140.

[2] W. Hoffmann, in Photovolt. Sustain. Electr. Build., Springer, Cham, 2017, pp. 55-93.

[3] B. Zakeri, S. Syri, Renew. Sustain. Energy Rev. 2015, 42, 569.

[4] N. S. Lewis, Science 2016, 351, aad1920.

[5] J. R. McKone, N. S. Lewis, H. B. Gray, Chem. Mater. 2014, 26, 407.

[6] J. R. Bolton, S. J. Strickler, J. S. Connolly, Nature 1985, 316, 495.

[7] T. Hisatomi, J. Kubota, K. Domen, Chem. Soc. Rev. 2014, 43, 7520.

[8] J. W. Ager, M. R. Shaner, K. A. Walczak, I. D. Sharp, S. Ardo, Energy Environ. Sci. 2015, 8, 2811.

[9] K. Sivula, R. van de Krol, Nat. Rev. Mater. 2016, 16010.

[10] J. H. Montoya, L. C. Seitz, P. Chakthranont, A. Vojvodic, T. F. Jaramillo, J. K. Nørskov, Nat. Mater. 2017, 16, 70.

[11] D. Bae, B. Seger, P. C. K. Vesborg, O. Hansen, I. Chorkendorff, Chem. Soc. Rev. 2017, 46, 1933.

[12] J. Seo, H. Nishiyama, T. Yamada, K. Domen, Angew. Chem. Int. Ed. 2018, 57, 8396.

[13] A. C. Nielander, M. R. Shaner, K. M. Papadantonakis, S. A. Francis, N. S. Lewis, Energy Environ. Sci. 2014, 8, 16.

[14] M. R. Shaner, H. A. Atwater, N. S. Lewis, E. W. McFarland, Energy Environ. Sci. 2016, 9, 2354.

[15] L. Dou, Y. Liu, Z. Hong, G. Li, Y. Yang, Chem. Rev. 2015, 115, 12633.

[16] H. Yao, L. Ye, H. Zhang, S. Li, S. Zhang, J. Hou, Chem. Rev. 2016, 116, 7397. 
[17] S. Zhang, L. Ye, J. Hou, Adv. Energy Mater. 2016, 6, 1502529.

[18] S. Xiao, Q. Zhang, W. You, Adv. Mater. 2017, 29, 1601391.

[19] G. Li, W.-H. Chang, Y. Yang, Nat. Rev. Mater. 2017, 2, 17043.

[20] J. Hou, O. Inganäs, R. H. Friend, F. Gao, Nat. Mater. 2018, 17, 119.

[21] Y. Cui, H. Yao, B. Gao, Y. Qin, S. Zhang, B. Yang, C. He, B. Xu, J. Hou, J. Am. Chem. Soc. 2017, 139, 7302.

[22] X. Xu, T. Yu, Z. Bi, W. Ma, Y. Li, Q. Peng, Adv. Mater. 2018, 30, 1703973.

[23] W. Zhao, S. Li, H. Yao, S. Zhang, Y. Zhang, B. Yang, J. Hou, J. Am. Chem. Soc. 2017, $139,7148$.

[24] L. Meng, Y. Zhang, X. Wan, C. Li, X. Zhang, Y. Wang, X. Ke, Z. Xiao, L. Ding, R. Xia, H.-L. Yip, Y. Cao, Y. Chen, Science 2018, eaat 2612.

[25] J. J. van Franeker, S. Kouijzer, X. Lou, M. Turbiez, M. M. Wienk, R. A. J. Janssen, Adv. Energy Mater. 2015, 5, 1500464.

[26] K. Zhang, Z. Chen, A. Armin, S. Dong, R. Xia, H.-L. Yip, S. Shoaee, F. Huang, Y. Cao, Sol. RRL 2018, 2, 1700169.

[27] F. C. Krebs, Sol. Energy Mater. Sol. Cells 2009, 93, 394.

[28] S. Kim, H. Kang, S. Hong, J. Lee, S. Lee, B. Park, J. Kim, K. Lee, Adv. Funct. Mater. 2016, 26, 3563.

[29] R. Søndergaard, M. Hösel, D. Angmo, T. T. Larsen-Olsen, F. C. Krebs, Mater. Today 2012, 15, 36.

[30] F. C. Krebs, N. Espinosa, M. Hösel, R. R. Søndergaard, M. Jørgensen, Adv. Mater. 2014, 26, 29.

[31] J. R. Swierk, T. E. Mallouk, Chem. Soc. Rev. 2013, 42, 2357.

[32] M. K. Brennaman, R. J. Dillon, L. Alibabaei, M. K. Gish, C. J. Dares, D. L. Ashford, R. L. House, G. J. Meyer, J. M. Papanikolas, T. J. Meyer, J. Am. Chem. Soc. 2016, 138, 13085.

[33] N. Queyriaux, N. Kaeffer, A. Morozan, M. Chavarot-Kerlidou, V. Artero, J. Photochem. Photobiol. C Photochem. Rev. 2015, 25, 90.

[34] E. A. Gibson, Chem. Soc. Rev. 2017, 46, 6194.

[35] G. Zhang, Z.-A. Lan, X. Wang, Angew. Chem. Int. Ed. 2016, 55, 15712.

[36] Y. Xu, M. Kraft, R. Xu, Chem. Soc. Rev. 2016, 45, 3039.

[37] V. S. Vyas, V. W. Lau, B. V. Lotsch, Chem. Mater. 2016, 28, 5191.

[38] S. Chen, Y. Liu, L. Zhang, P. C. Y. Chow, Z. Wang, G. Zhang, W. Ma, H. Yan, J. Am. Chem. Soc. 2017, 139, 6298.

[39] P. Cheng, M. Zhang, T.-K. Lau, Y. Wu, B. Jia, J. Wang, C. Yan, M. Qin, X. Lu, X. Zhan, Adv. Mater. 2017, 29, 1605216.

[40] A. Aoki, M. Naruse, T. Abe, Mol. Cryst. Liq. Cryst. 2011, 538, 182.

[41] A. Atsushi, N. Mitsuru, A. Takayuki, ChemPhysChem 2013, 14, 2317.

[42] T. Ameri, G. Dennler, C. Lungenschmied, C. J. Brabec, Energy Environ. Sci. 2009, 2, 347.

[43] T. Ameri, N. Li, C. J. Brabec, Energy Environ. Sci. 2013, 6, 2390.

[44] X. Xiao, K. Lee, S. R. Forrest, Appl. Phys. Lett. 2015, 106, 213301.

[45] M. S. Prévot, K. Sivula, J. Phys. Chem. C 2013, 117, 17879.

[46] M. G. Walter, E. L. Warren, J. R. McKone, S. W. Boettcher, Q. Mi, E. A. Santori, N. S. Lewis, Chem. Rev. 2010, 110, 6446.

[47] C. C. L. McCrory, S. Jung, I. M. Ferrer, S. M. Chatman, J. C. Peters, T. F. Jaramillo, J. Am. Chem. Soc. 2015, 137, 4347.

[48] W. J. Youngblood, S.-H. A. Lee, Y. Kobayashi, E. A. Hernandez-Pagan, P. G. Hoertz, T. A. Moore, A. L. Moore, D. Gust, T. E. Mallouk, J. Am. Chem. Soc. 2009, 131, 926.

[49] M. Grätzel, Inorg. Chem. 2005, 44, 6841.

[50] R. Jose, V. Thavasi, S. Ramakrishna, J. Am. Ceram. Soc. 2009, 92, 289. 
[51] Y. Luo, D. Li, Q. Meng, Adv. Mater. 2009, 21, 4647.

[52] Z. Yu, F. Li, L. Sun, Energy Environ. Sci. 2015, 8, 760.

[53] P. Xu, N. S. McCool, T. E. Mallouk, Nano Today 2017, 14, 42.

[54] B. A. Pinaud, J. D. Benck, L. C. Seitz, A. J. Forman, Z. Chen, T. G. Deutsch, B. D. James, K. N. Baum, G. N. Baum, S. Ardo, H. Wang, E. Miller, T. F. Jaramillo, Energy Environ. Sci. 2013, 6, 1983.

[55] D. M. Fabian, S. Hu, N. Singh, F. A. Houle, T. Hisatomi, K. Domen, F. E. Osterloh, S. Ardo, Energy Environ. Sci. 2015, 8, 2825.

[56] S. Chu, W. Li, Y. Yan, T. Hamann, I. Shih, D. Wang, Z. Mi, Nano Futur. 2017, 1, 022001.

[57] V. Artero, M. Fontecave, Chem. Soc. Rev. 2013, 42, 2338.

[58] Y.-L. Wong, J. M. Tobin, Z. Xu, F. Vilela, J. Mater. Chem. A 2016, 4, 18677.

[59] W. Zhang, W. Lai, R. Cao, Chem. Rev. 2017, 117, 3717.

[60] S. Esiner, H. van Eersel, G. W. P. van Pruissen, M. Turbiez, M. M. Wienk, R. A. J. Janssen, ACS Appl. Mater. Interfaces 2016, 8, 26972.

[61] M. Li, K. Gao, X. Wan, Q. Zhang, B. Kan, R. Xia, F. Liu, X. Yang, H. Feng, W. Ni, Y. Wang, J. Peng, H. Zhang, Z. Liang, H.-L. Yip, X. Peng, Y. Cao, Y. Chen, Nat. Photonics 2017, 11, 85.

[62] S. Chen, G. Zhang, J. Liu, H. Yao, J. Zhang, T. Ma, Z. Li, H. Yan, Adv. Mater. 2017, 29, 1604231.

[63] R. Kang, S. Park, Y. K. Jung, D. C. Lim, M. J. Cha, J. H. Seo, S. Cho, Adv. Energy Mater. 2018, 1702165.

[64] S. Esiner, H. van Eersel, M. M. Wienk, R. A. J. Janssen, Adv. Mater. 2013, 25, 2932.

[65] S. Esiner, R. E. M. Willems, A. Furlan, W. Li, M. M. Wienk, R. A. J. Janssen, J. Mater. Chem. A 2015, 3, 23936.

[66] H. Zhou, Y. Zhang, C.-K. Mai, S. D. Collins, G. C. Bazan, T.-Q. Nguyen, A. J. Heeger, Adv. Mater. 2015, 27, 1767.

[67] Y. Gao, V. M. Le Corre, A. Gaïtis, M. Neophytou, M. A. Hamid, K. Takanabe, P. M. Beaujuge, Adv. Mater. 2016, 28, 3366.

[68] S. Esiner, G. W. P. van Pruissen, M. M. Wienk, R. A. J. Janssen, J. Mater. Chem. A 2016, 4, 5107.

[69] X. Elias, Q. Liu, C. Gimbert-Suriñach, R. Matheu, P. Mantilla-Perez, A. Martinez-Otero, X. Sala, J. Martorell, A. Llobet, ACS Catal. 2016, 6, 3310.

[70] J. L. Young, M. A. Steiner, H. Döscher, R. M. France, J. A. Turner, T. G. Deutsch, Nat. Energy 2017, 2, 17028.

[71] J. Luo, J.-H. Im, M. T. Mayer, M. Schreier, M. K. Nazeeruddin, N.-G. Park, S. D. Tilley, H. J. Fan, M. Grätzel, Science 2014, 345, 1593.

[72] T. Jesper Jacobsson, V. Fjällström, M. Sahlberg, M. Edoff, T. Edvinsson, Energy Environ. Sci. 2013, 6, 3676.

[73] L. Zuo, J. Yu, X. Shi, F. Lin, W. Tang, A. K.-Y. Jen, Adv. Mater. 2017, 29, 1702547.

[74] S. M. Menke, N. A. Ran, G. C. Bazan, R. H. Friend, Joule 2018, 2, 25.

[75] M. Giannouli, V. M. Drakonakis, A. Savva, P. Eleftheriou, G. Florides, S. A. Choulis, ChemPhysChem 2015, 16, 1134.

[76] O. A. El-Rashiedy, S. Holdcroft, J. Phys. Chem. 1996, 100, 5481.

[77] G. Suppes, E. Ballard, S. Holdcroft, Polym. Chem. 2013, 4, 5345.

[78] M. Urien, G. Wantz, E. Cloutet, L. Hirsch, P. Tardy, L. Vignau, H. Cramail, J.-P. Parneix, Org. Electron. 2007, 8, 727.

[79] C. H. Ng, O. Winther-Jensen, B. Kolodziejczyk, C. A. Ohlin, B. Winther-Jensen, Int. J. Hydrog. Energy 2014, 39, 18230.

[80] C. H. Ng, O. Winther-Jensen, C. A. Ohlin, B. Winther-Jensen, J. Mater. Chem. A 2015, 3,11358 
[81] K. Oka, O. Tsujimura, T. Suga, H. Nishide, B. Winther-Jensen, Energy Environ. Sci. 2018, 11, 1335.

[82] Y. Wang, X. Wang, M. Antonietti, Angew. Chem. Int. Ed. 2012, 51, 68.

[83] Y. Zheng, L. Lin, B. Wang, X. Wang, Angew. Chem. Int. Ed. 2015, 54, 12868.

[84] K. Schwinghammer, S. Hug, M. B. Mesch, J. Senker, B. V. Lotsch, Energy Environ. Sci. 2015, 8, 3345.

[85] X. Jiang, P. Wang, J. Zhao, J. Mater. Chem. A 2015, 3, 7750.

[86] R. S. Sprick, J.-X. Jiang, B. Bonillo, S. Ren, T. Ratvijitvech, P. Guiglion, M. A. Zwijnenburg, D. J. Adams, A. I. Cooper, J. Am. Chem. Soc. 2015, 137, 3265.

[87] L. Li, Z. Cai, Q. Wu, W.-Y. Lo, N. Zhang, L. X. Chen, L. Yu, J. Am. Chem. Soc. 2016, $138,7681$.

[88] V. S. Vyas, F. Haase, L. Stegbauer, G. Savasci, F. Podjaski, C. Ochsenfeld, B. V. Lotsch, Nat. Commun. 2015, 6, 8508.

[89] T. Banerjee, F. Haase, G. Savasci, K. Gottschling, C. Ochsenfeld, B. V. Lotsch, J. Am. Chem. Soc. 2017, 139, 16228.

[90] T. Sick, A. G. Hufnagel, J. Kampmann, I. Kondofersky, M. Calik, J. M. Rotter, A. Evans, M. Döblinger, S. Herbert, K. Peters, D. Böhm, P. Knochel, D. D. Medina, D.

Fattakhova-Rohlfing, T. Bein, J. Am. Chem. Soc. 2018, 140, 2085.

[91] L. Yao, A. Rahmanudin, X. A. Jeanbourquin, X. Yu, M. Johnson, N. Guijarro, A. Sekar, K. Sivula, Adv. Funct. Mater. 2018, 28, 1706303.

[92] T. Abe, K. Nagai, K. Sekimoto, A. Tajiri, T. Norimatsu, Electrochem. Commun. 2005, 7, 1129.

[93] T. Abe, S. Tobinai, K. Nagai, Jpn. J. Appl. Phys. 2009, 48, 021503.

[94] E. Lanzarini, M. R. Antognazza, M. Biso, A. Ansaldo, L. Laudato, P. Bruno, P. Metrangolo, G. Resnati, D. Ricci, G. Lanzani, J. Phys. Chem. C 2012, 116, 10944.

[95] T. Bourgeteau, D. Tondelier, B. Geffroy, R. Brisse, C. Laberty-Robert, S. Campidelli, R. de Bettignies, V. Artero, S. Palacin, B. Jousselme, Energy Environ. Sci. 2013, 6, 2706.

[96] M. T. Dang, L. Hirsch, G. Wantz, Adv. Mater. 2011, 23, 3597.

[97] W. Cao, J. Xue, Energy Environ. Sci. 2014, 7, 2123.

[98] K. Wang, C. Liu, T. Meng, C. Yi, X. Gong, Chem. Soc. Rev. 2016, 45, 2937.

[99] T. Bourgeteau, D. Tondelier, B. Geffroy, R. Brisse, S. Campidelli, R. Cornut, B. Jousselme, J. Mater. Chem. A 2016, 4, 4831.

[100] M. Haro, C. Solis, G. Molina, L. Otero, J. Bisquert, S. Gimenez, A. Guerrero, J. Phys. Chem. C 2015, 119, 6488.

[101] S. Bellani, L. Najafi, A. Capasso, A. E. D. R. Castillo, M. Rosa Antognazza, F. Bonaccorso, J. Mater. Chem. A 2017, 5, 4384.

[102] L. Steier, S. Bellani, H. Comas Rojas, L. Pan, M. Laitinen, T. Sajavaara, F. D. Fonzo, M. Grätzel, M. Rosa Antognazza, M. T. Mayer, Sustain. Energy Fuels 2017, 1, 1915.

[103] F. Fumagalli, S. Bellani, M. Schreier, S. Leonardi, H. Comas Rojas, A. Ghadirzadeh, G. Tullii, A. Savoini, G. Marra, L. Meda, M. Grätzel, G. Lanzani, M. T. Mayer, M. Rosa Antognazza, F. D. Fonzo, J. Mater. Chem. A 2016, 4, 2178.

[104] M. Haro, C. Solis, V. M. Blas-Ferrando, O. Margeat, S. B. Dhkil, C. VidelotAckermann, J. Ackermann, F. Di Fonzo, A. Guerrero, S. Gimenez, ChemSusChem 2016, 9, 3062.

[105] T. Bourgeteau, D. Tondelier, B. Geffroy, R. Brisse, R. Cornut, V. Artero, B. Jousselme, ACS Appl. Mater. Interfaces 2015, 7, 16395.

[106] L. Francàs, E. Burns, L. Steier, H. Cha, L. Solà-Hernández, X. Li, P. S. Tuladhar, R. Bofill, J. García-Antón, X. Sala, J. R. Durrant, Chem. Commun. 2018, 54, 5732.

[107] H. Comas Rojas, S. Bellani, F. Fumagalli, G. Tullii, S. Leonardi, M. T. Mayer, M. Schreier, M. Grätzel, G. Lanzani, F. D. Fonzo, M. Rosa Antognazza, Energy Environ. Sci. 2016, 9, 3710. 
[108] Z. Chen, T. F. Jaramillo, T. G. Deutsch, A. Kleiman-Shwarsctein, A. J. Forman, N. Gaillard, R. Garland, K. Takanabe, C. Heske, M. Sunkara, E. W. McFarland, K. Domen, E. L. Miller, J. A. Turner, H. N. Dinh, J. Mater. Res. 2010, 25, 3.

[109] D. Shao, L. Zheng, D. Feng, J. He, R. Zhang, H. Liu, X. Zhang, Z. Lu, W. Wang, W. Wang, F. Lu, H. Dong, Y. Cheng, H. Liu, R. Zheng, J. Mater. Chem. A 2018, 6, 4032.

[110] T. Abe, K. Fukui, Y. Kawai, K. Nagai, H. Kato, Chem. Commun. 2016, 52, 7735.

[111] H. Comas Rojas, S. Bellani, E. A. Sarduy, F. Fumagalli, M. T. Mayer, M. Schreier, M. Grätzel, F. Di Fonzo, M. R. Antognazza, ACS Omega 2017, 2, 3424.

[112] S. Bellani, L. Najafi, B. Martin-García, A. Ansaldo, A. E. Del Rio Castillo, M. Prato, I. Moreels, F. Bonaccorso, J. Phys. Chem. C 2017, 121, 21887.

[113] J. T. Kirner, R. G. Finke, J. Mater. Chem. A 2017, 5, 19560.

[114] Y. Gao, X. Ding, J. Liu, L. Wang, Z. Lu, L. Li, L. Sun, J. Am. Chem. Soc. 2013, 135, 4219.

[115] Abe, Toshiyuki, K. Nagai, Kabutomori, Satoko, Kaneko, Masao, Tajiri, Akio, Norimatsu, Takayoshi, Angew. Chem. Int. Ed. 2006, 45, 2778.

[116] G. Liu, C. Chen, H. Ji, W. Ma, J. Zhao, Sci. China Chem. 2012, 55, 1953.

[117] J. T. Kirner, J. J. Stracke, B. A. Gregg, R. G. Finke, ACS Appl. Mater. Interfaces 2014, 6, 13367.

[118] L. Wang, D. Yan, D. W. Shaffer, X. Ye, B. H. Layne, J. J. Concepcion, M. Liu, C.-Y. Nam, Chem. Mater. 2018, 30, 324.

[119] P. Bornoz, M. S. Prévot, X. Yu, N. Guijarro, K. Sivula, J. Am. Chem. Soc. 2015, 137, 15338.

[120] A. Babel, S. A. Jenekhe, J. Am. Chem. Soc. 2003, 125, 13656.

[121] M. M. Alam, S. A. Jenekhe, Chem. Mater. 2004, 16, 4647.

[122] J. Luo, L. Steier, M.-K. Son, M. Schreier, M. T. Mayer, M. Grätzel, Nano Lett. 2016, $16,1848$.

[123] L. Pan, J. H. Kim, M. T. Mayer, M.-K. Son, A. Ummadisingu, J. S. Lee, A. Hagfeldt, J. Luo, M. Grätzel, Nat. Catal. 2018, 1, 412.

[124] M. H. Lee, K. Takei, J. Zhang, R. Kapadia, M. Zheng, Y.-Z. Chen, J. Nah, T. S. Matthews, Y.-L. Chueh, J. W. Ager, A. Javey, Angew. Chem. Int. Ed. 2012, 51, 10760.

[125] J. R. McKone, A. P. Pieterick, H. B. Gray, N. S. Lewis, J. Am. Chem. Soc. 2013, 135, 223.

[126] J. Zhao, T. Minegishi, L. Zhang, M. Zhong, Gunawan, M. Nakabayashi, G. Ma, T. Hisatomi, M. Katayama, S. Ikeda, N. Shibata, T. Yamada, K. Domen, Angew. Chem. Int. Ed. 2014, 53, 11808.

[127] N. Guijarro, M. S. Prévot, X. Yu, X. A. Jeanbourquin, P. Bornoz, W. Bourée, M. Johnson, F. Le Formal, K. Sivula, Adv. Energy Mater. 2016, 6, 1501949.

[128] W. Yang, Y. Oh, J. Kim, M. J. Jeong, J. H. Park, J. Moon, ACS Energy Lett. 2016, 1, 1127.

[129] F. Jiang, Gunawan, T. Harada, Y. Kuang, T. Minegishi, K. Domen, S. Ikeda, J. Am. Chem. Soc. 2015, 137, 13691.

[130] X. Yu, N. Guijarro, M. Johnson, K. Sivula, Nano Lett. 2018, 18, 215.

[131] A. Morozan, T. Bourgeteau, D. Tondelier, B. Geffroy, B. Jousselme, V. Artero, Nanotechnology 2016, 27, 355401.

[132] P. Cheng, X. Zhan, Chem. Soc. Rev. 2016, 45, 2544.

[133] H. Cha, J. Wu, A. Wadsworth, J. Nagitta, S. Limbu, S. Pont, Z. Li, J. Searle, M. F. Wyatt, D. Baran, J.-S. Kim, I. McCulloch, J. R. Durrant, Adv. Mater. 2017, 29, 1701156.

[134] D. Baran, R. S. Ashraf, D. A. Hanifi, M. Abdelsamie, N. Gasparini, J. A. Röhr, S. Holliday, A. Wadsworth, S. Lockett, M. Neophytou, C. J. M. Emmott, J. Nelson, C. J. Brabec, A. Amassian, A. Salleo, T. Kirchartz, J. R. Durrant, I. McCulloch, Nat. Mater. 2017, 16, 363 . 
[135] M. Liu, Y. Gao, Y. Zhang, Z. Liu, L. Zhao, Polym. Chem. 2017, 8, 4613.

[136] K. Zhang, M. Ma, P. Li, D. H. Wang, J. H. Park, Adv. Energy Mater. 2016, 6, 1600602. 

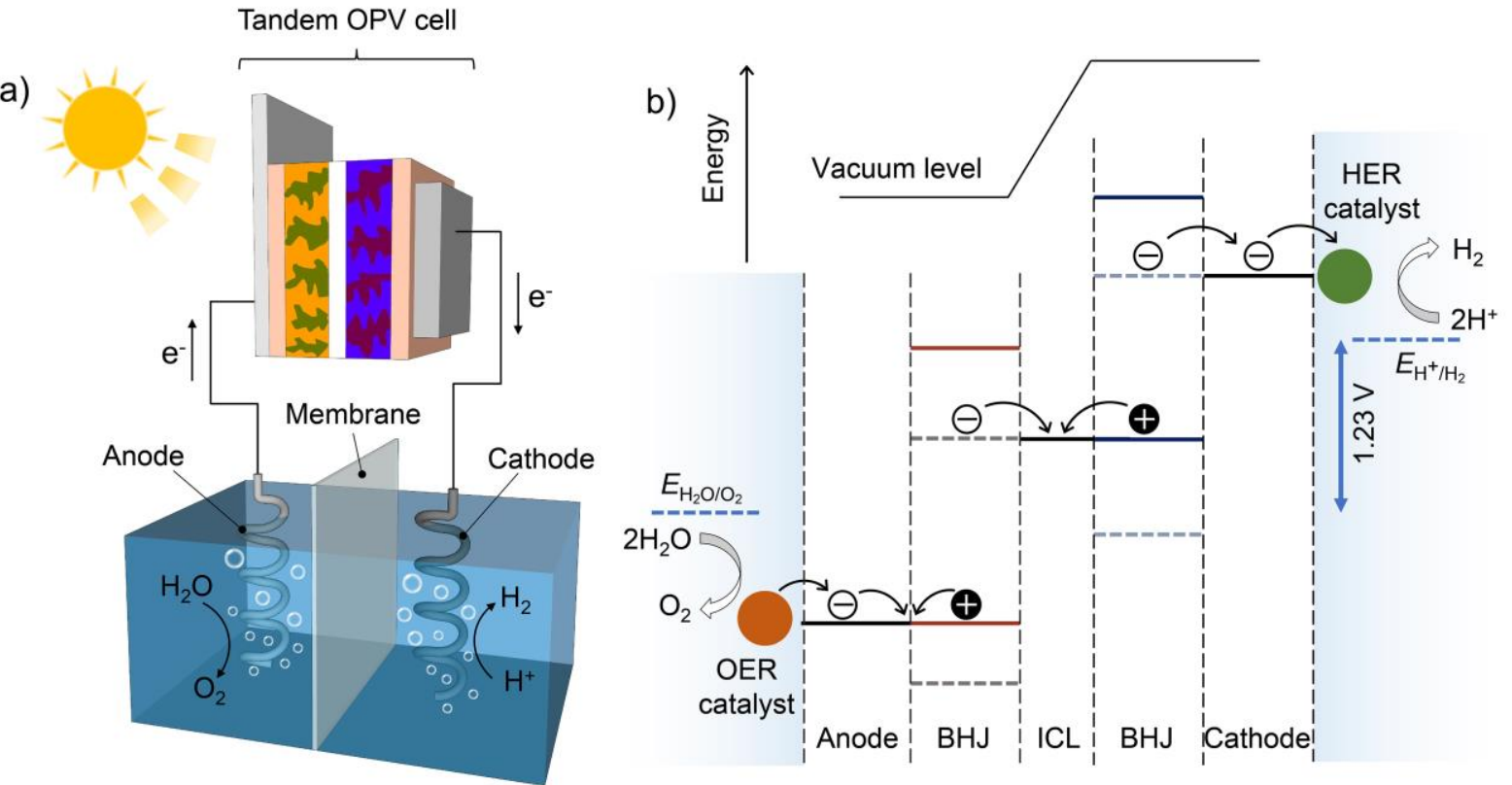

Figure 1. a) Schematic representation for OPV-biased water splitting using a double BHJ junction tandem cell wired to an electrolysis cell. The cathode and the anode drive the water reduction and oxidation half-reactions, respectively, and a membrane separates the evolved $\mathrm{H}_{2}$ and $\mathrm{O}_{2}$ gasses. b) The energy level diagram of a double BHJ junction tandem OPV device and the operation of water splitting reactions. ICL represents the intermediate contact layer in the tandem OPV device. The solid and dash line is the energy level of the donor and the acceptor in the BHJ, respectively. The total photopotential developed by the cell is represented by the difference in the energy of the cathode and the anode. Charge transfer to the electrolyte and the electrochemical reactions are mediated by the OER and HER catalysts. 
a)

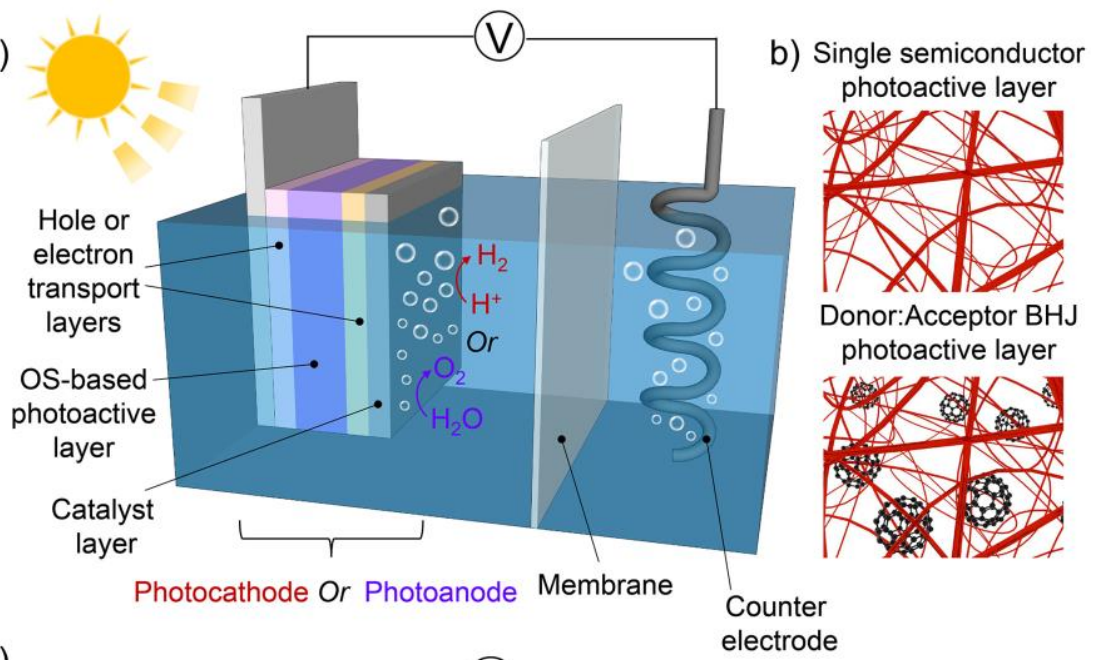

c)

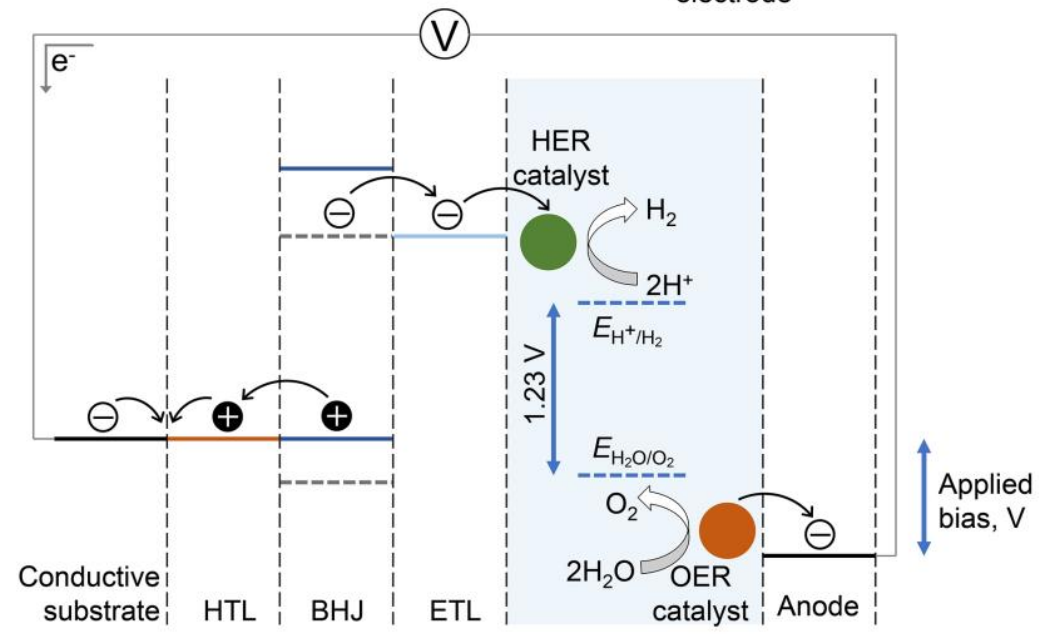

d)

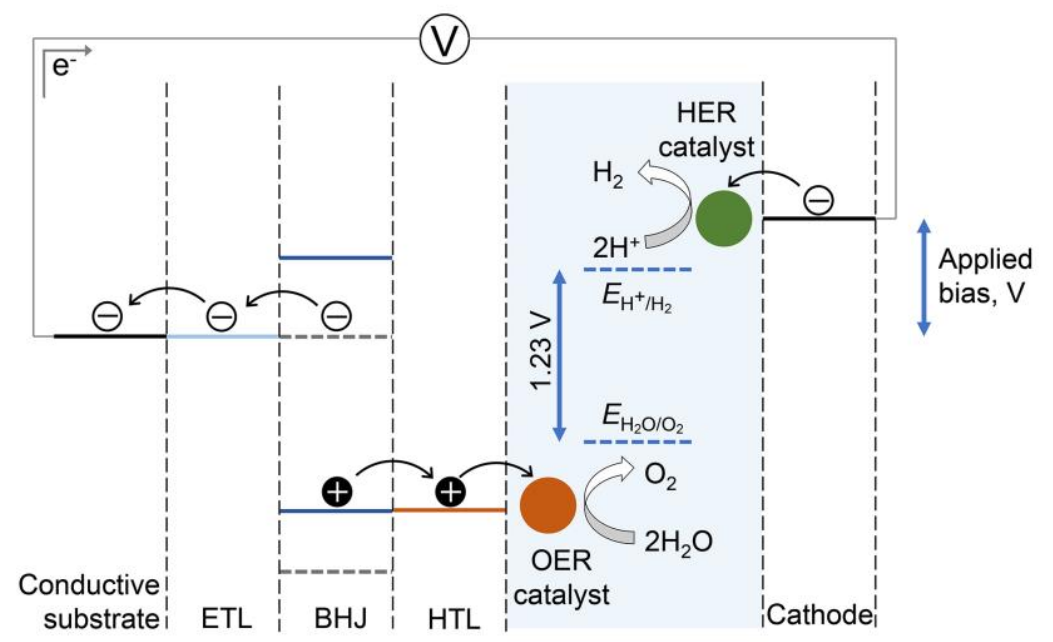

Figure 2. a) Schematic representation for a photoelectrochemical cell based on organic semiconductor photocathode or photoanode. b) Scheme representation for the photoactive layer based on a single semiconductor (e.g. a conjugated polymer) or a donor:acceptor polymer:fullerene BHJ. c) The energy level diagram of photocathode/anode PEC cell with applied bias for overall water splitting. d) The energy level diagram of photoanode/cathode PEC cell with applied bias for overall water splitting. ETL and HTL represent the electron transport layer and hole transport layer, respectively. The solid and dash line is the energy level of the donor and the acceptor in the BHJ, respectively. 


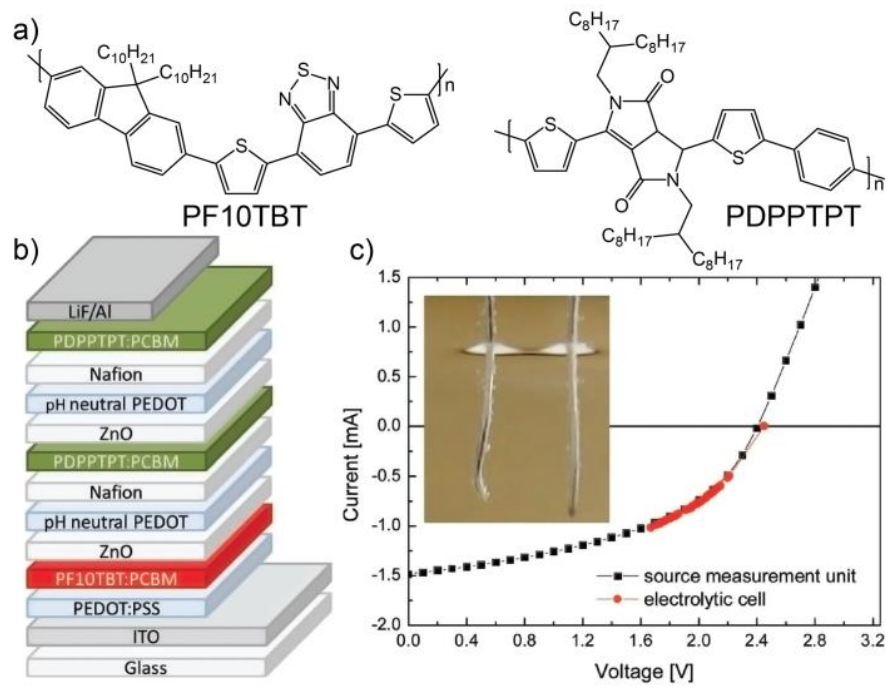

Figure 3. Solar water splitting with a triple junction OPV. a) Structures of the wide bandgap $\left(\right.$ PF10TBT, $E_{\mathrm{g}}=1.95 \mathrm{eV}$ ) and small bandgap (PDPPTPT, $E_{\mathrm{g}}=1.53 \mathrm{eV}$ ) polymers used in the BHJ active layers (with PCBM). b) Schematic layout of the $1+2$ type triple junction solar cell. The red BHJ is the wide bandgap and the green BHJs are the small bandgap. c) Comparison of the I-V curves of the triple junction cell measured using a water electrolysis cell with different sized contacts and using a source-measurement unit. This particular triple junction cell had $\mathrm{V}_{\mathrm{oc}}=2.50 \mathrm{~V}$ when measured under white light conditions close to AM1.5G. The inset shows the evolution of $\mathrm{H}_{2}$ and $\mathrm{O}_{2}$ from the $\mathrm{Pt}$ cathode and anode during the experiment. Adapted with permission. ${ }^{[64]}$ (C) 2013 WILEY-VCH Verlag GmbH \& Co. KGaA, Weinheim 
a)

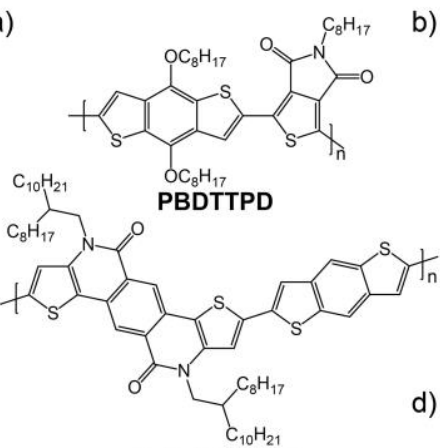

PTPTIBDT-OD

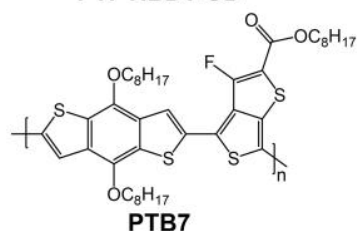

b)
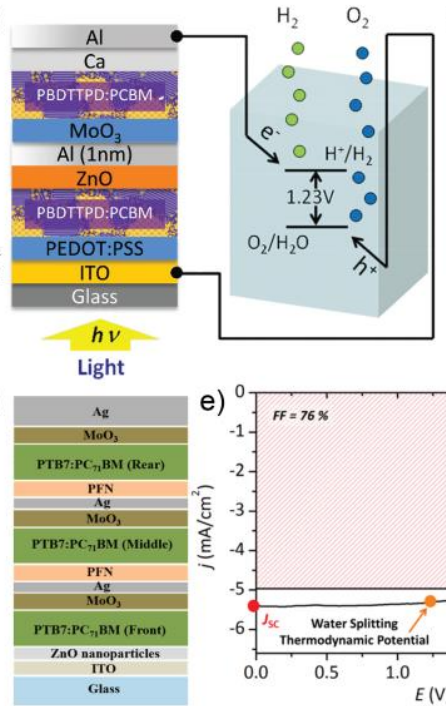
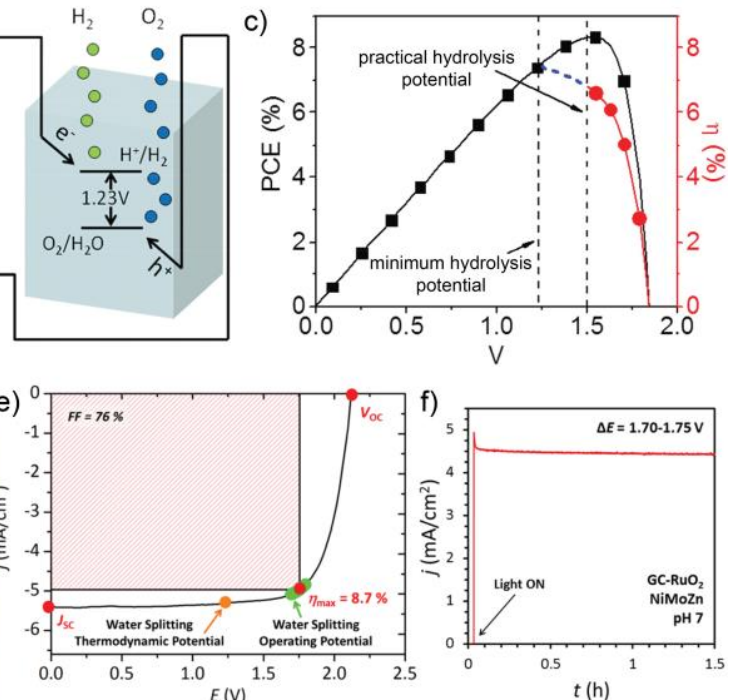

Figure 4. Homo-tandem OPVs for solar water splitting. a) Molecular structures of the donor polymers used in the active layers of the homo-tandem OPVs mentioned in the main text. b) Schematic of the double junction PBDTTPD-based device. c) Power conversion efficiency (PCE) of the PBDTTPD-based cell (measured via source-measurement unit) and the estimated solar-to-hydrogen conversion efficiency $(\eta)$ as functions of the operating voltage, $\mathrm{V}$. d) Schematic representation of the triple junction PTB7 based cell (PFN is poly[(9,9-bis(3'(N,N-dimethylamino)propyl)-2,7-fluorene)-alt-2,7-(9,9-dioctylfluorene)]) e) current density, j, versus potential, E, curve of the triple junction cell where the water splitting thermodynamic potential (orange) and water splitting operating potential range (green) are indicated. f) Current density vs time profile of a water splitting experiment using a triple junction solar cell with a GC- $\mathrm{RuO}_{2}$ anode and SST-NiMoZn cathode in a two electrode configuration and a two compartment cell containing $0.1 \mathrm{M}$ phosphate buffer, $\mathrm{pH}=7.0$, under AM $1.5 \mathrm{G}$ illumination with a GG400 filter. Figures (b)-(c) are adapted with permission. $\left.{ }^{[67]}{ }^{(}\right) 2016$ WILEY-VCH Verlag GmbH \& Co. KGaA, Weinheim. Figures (d)-(f) are adapted with permission. ${ }^{[69]}$ (C) 2016 American Chemical Society. 

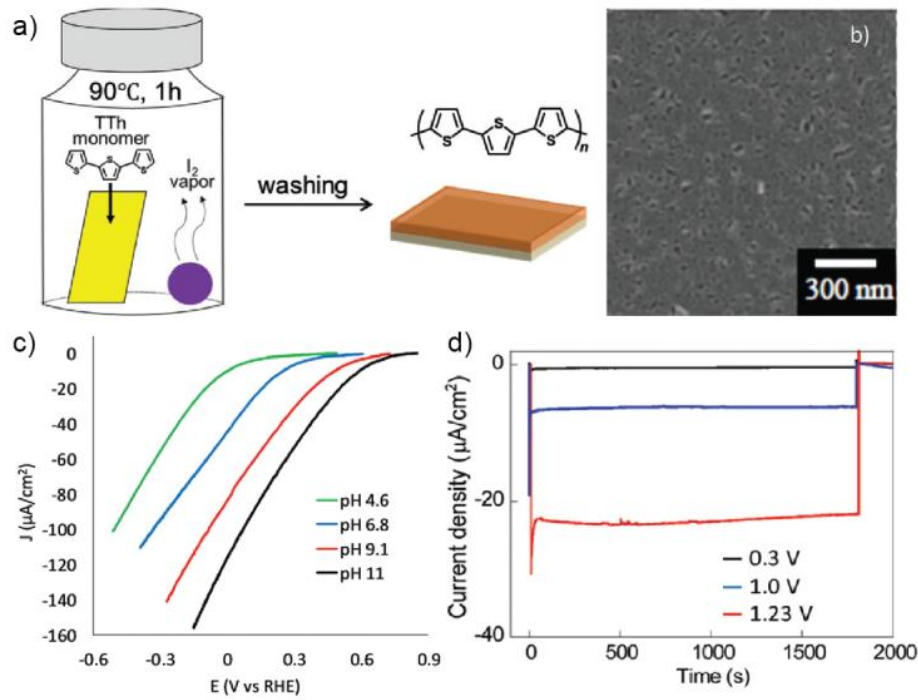

Figure 5. (a) Schematic of the iodine-vapor-assisted polymerization procedure for terthiophene (TTh) polymerization. The as-polymerized PTTh films are in the oxidized (conducting) state, and are reduced during washing in ethanol or acetonitrile by the removal of excess $\mathrm{I}_{2}$ and $\mathrm{I}^{-}$. (b) SEM image of the optimized PTTh film. (c) Linear Scanning voltammetry of the PTTh photocathode at $1 \mathrm{mV} \mathrm{s}^{-1}$ under illumination at different $\mathrm{pH}$. (d) Chronoamperometry measurements on a two-electrode PEC cell with a PTTh photocathode and a $\mathrm{MnO}_{\mathrm{x}}$ anode at $\mathrm{pH} 12(0.1 \mathrm{M}$ sodium phosphate/ sodium hydrogen-phosphate buffer) with various applied bias potentials (vs. $\mathrm{MnO}_{\mathrm{x}}$ ). Adapted with permission. ${ }^{[81]}$ (OThe Royal Society of Chemistry 2018.

a)
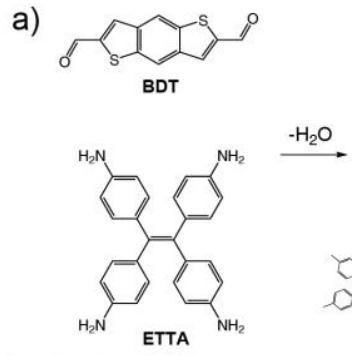

b)

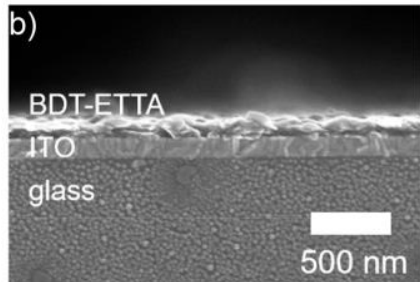

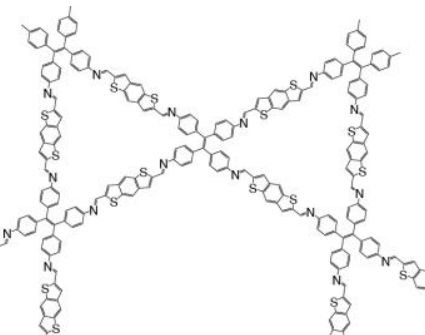

c)
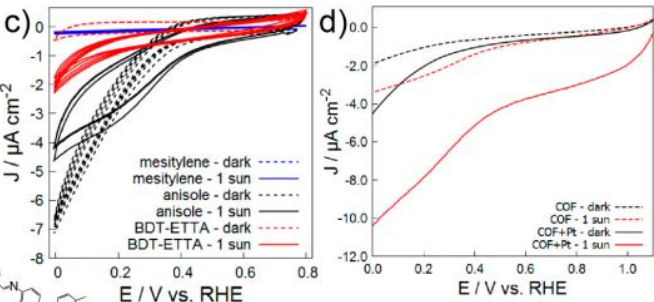

Or $/$ V vs. RHE

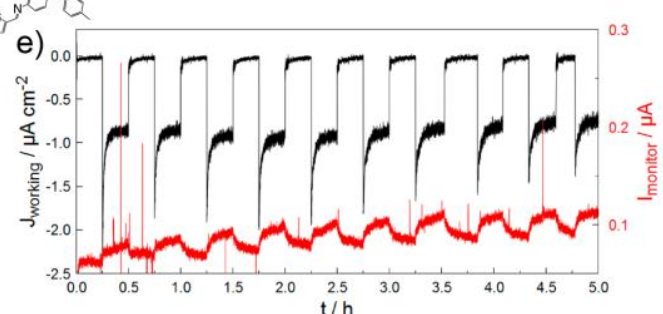

Figure 6. a) Synthetic approach for the formation of BDT-ETTA COF with a structural overview of the resulting 2D layers. b) SEM image (cross-section) of a thin (ca. $100 \mathrm{~nm}$ ) BDT-ETTA film grown on ITO substrate. c) Cyclic voltammograms (in nitrogen-purged 0.1 $\mathrm{M} \mathrm{Na}_{2} \mathrm{SO}_{4}$ aqueous electrolyte) of BDT-ETTA films grown from different solvents onto ITO measured in the dark and under illumination (AM 1.5 substrate side). The red curves represent the COF grown in a mesitylene-dioxane mixture. d) Linear sweep voltammograms of BDTETTA films on ITO in the dark (black) and under (red) with platinum nanoparticles (solid lines) compared to bare BDT-ETTA films (dashed lines). e) Chronoamperometric data recorded on a BDT-ETTA film at $+0.4 \mathrm{~V}$ vs. RHE (black) under chopped AM 1.5 illumination. Oxidation current recorded simultaneously on a platinum mesh indicator electrode (red) indicates the formation of hydrogen under illumination. Adapted with permission. ${ }^{[90]}$ (C) 2018 American Chemical Society. 

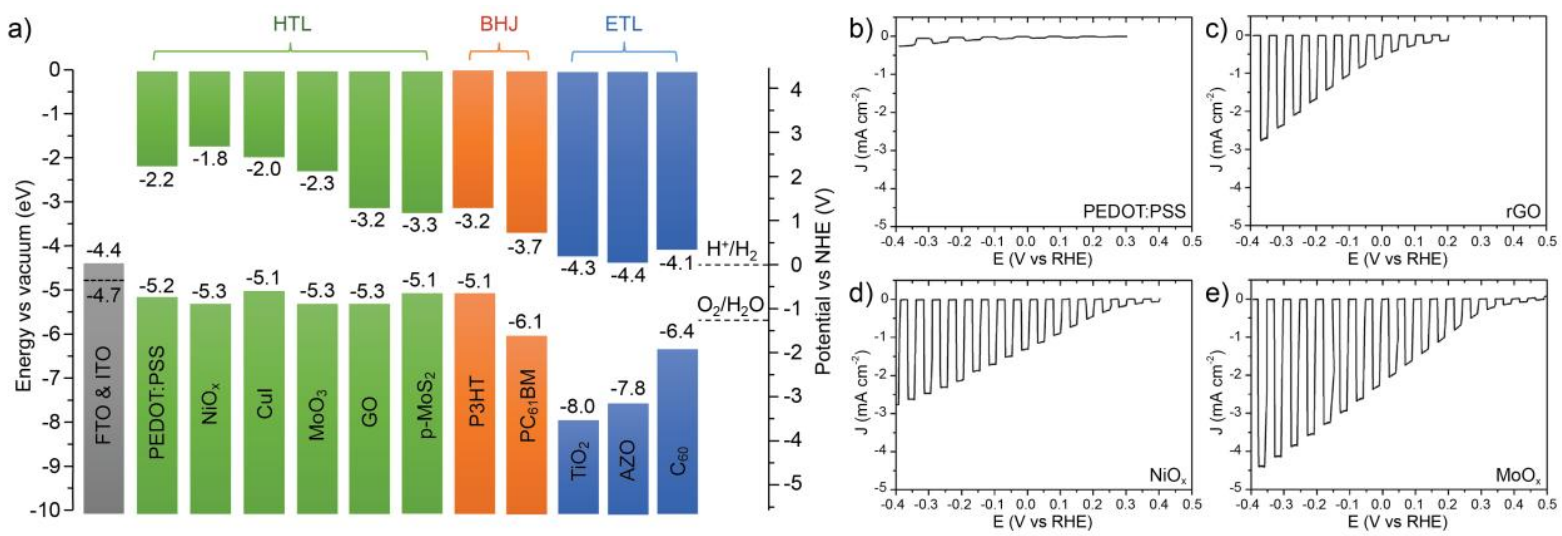

Figure 7. Hole transport layers (HTLs) and electron transport layers (ETLs) used in organic photocathodes. (a) Shows a summary of the literature reported energy levers of materials used in photocathodes with reference to the $\mathrm{BHJ}$ of $\mathrm{P} 3 \mathrm{HT}: \mathrm{PC}_{61} \mathrm{BM}$ and the water redox potentials. (b-e) Show the effect of the HTL on a P3HT:PC ${ }_{61} \mathrm{BM}$ based photocathode with linear scanning voltammograms recorded at $50 \mathrm{mV} \mathrm{s}^{-1}$ in $0.5 \mathrm{M} \mathrm{H}_{2} \mathrm{SO}_{4}$ with intermittent visible light for $\quad \mathrm{a}$ (b) ITO/PEDOT:PSS/P3HT:PCBM/MoS 3 photocathode, (c) ITO/rGO/P3HT:PCBM/MoS 3 photocathode, (d) ITO/NiOx/P3HT:PCBM/MoS 3 photocathode and (e) ITO/MoO $/ \mathrm{P} 3 \mathrm{HT}: \mathrm{PCBM} / \mathrm{MoS}_{3}$ photocathode. Electrode area: $0.28 \mathrm{~cm}^{2}$. Figures (b-e) adapted with permission. ${ }^{[99]}$ (C) 2016 The Royal Society of Chemistry.

a)
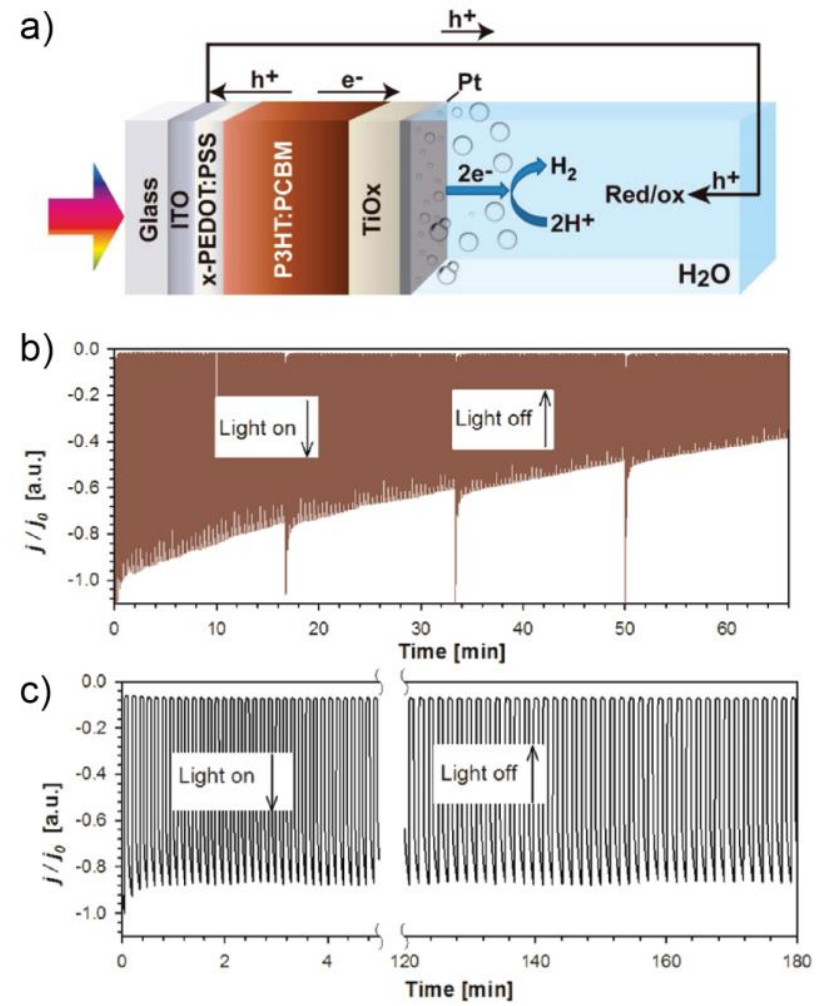

Figure 8. (a) Photocathode architecture used to examine $\mathrm{TiO}_{\mathrm{x}}$ thickness. (b-c) Normalized chronoamperometry measurements $\left(\mathrm{j} / \mathrm{j}_{0}\right)$ for the configuration glass/ITO/x-PEDOT:PSS (cross-linked) /P3HT:PCBM/TiO $/ \mathrm{Pt}$ in aqueous $\mathrm{Na}_{2} \mathrm{SO}_{4}(0.1 \mathrm{M}, \mathrm{pH}$ 2) under intermittent illumination. (b) shows results when a thin layer of $\mathrm{TiO}_{\mathrm{x}}(40 \mathrm{~nm})$ was measured at $0.15 \mathrm{~V}$ vs RHE while (c) shows a thick layer of $\mathrm{TiO}_{\mathrm{x}}(150 \mathrm{~nm})$ measured at $0 \mathrm{~V}$ versus RHE. Adapted with permission. ${ }^{[100]}$ (C) 2015 American Chemical Society. 

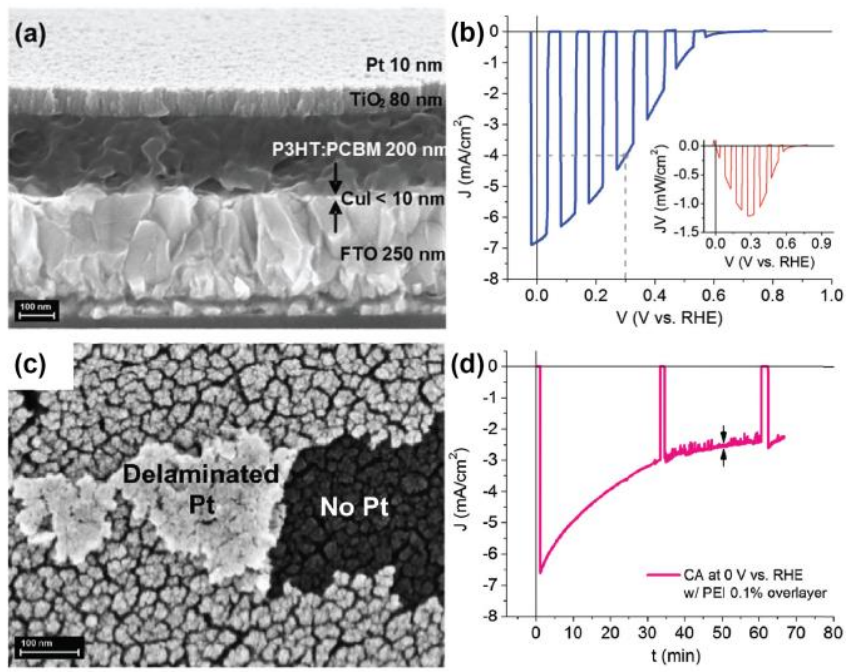

Figure 9. a) Cross-sectional SEM view of the photocathode from Comas Rojas et al. ${ }^{[107]}$ showing its inner structure and nominal thicknesses of each layer (scale bar $100 \mathrm{~nm}$ ). b) Photoelectrochemical characterization in $\mathrm{pH} 1$ electrolyte with a representative LSV scan of a photocathode under chopped light illumination (AM $1.5 \mathrm{G}$ ) and identification of the maximum power point (inset). c) SEM micrographs of the surface (capping Pt layer on top of the nanostructured $\mathrm{TiO}_{2}$ ) after one-hour operation at $0 \mathrm{~V}$ vs. RHE, $\mathrm{pH} 1$ and 1 sun illumination showing Pt delamination and fragments folded back (scale bar $100 \mathrm{~nm}$ ). d) Effect of the PEI over-layer at $\mathrm{pH} 1$ and AM 1.5 illumination with a CA test at $0 \mathrm{~V}$ vs. RHE of the protected photocathode. The vertical double arrows indicate the time when $60 \%$ loss of the photocurrent occurs. Adapted under the terms of the CC BY-NC 3.0 license. ${ }^{[107]}$

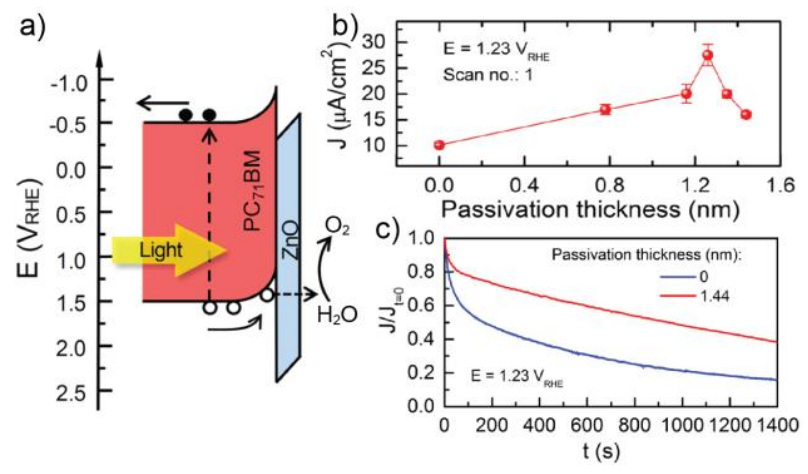

Figure 10. a) Schematic energy band diagram depicting the band alignment between the $\mathrm{PC}_{71} \mathrm{BM}$ thin film and $\mathrm{ZnO}$ passivation layer. b) Average $\mathrm{J}_{\mathrm{ph}}$ measured during the first PEC scan cycle with respect to the $\mathrm{ZnO}$ passivation thickness at $\mathrm{E}=1.23 \mathrm{~V}$ vs RHE (in $0.1 \mathrm{M}$ $\mathrm{KOH}$ solution $\mathrm{pH} \sim 13$ ) under AM1.5G solar illumination. c) Representative PEC water oxidation chronoamperometry $\left(\mathrm{J}-\mathrm{t}\right.$ ) behavior (normalized to $\mathrm{J} @ \mathrm{t}=0$ ) of $\mathrm{PC}_{71} \mathrm{BM}$ thin film photoanodes with $1.44 \mathrm{~nm}$-thick $\mathrm{ZnO}$ passivation (red) and without passivation (blue), obtained in $0.1 \mathrm{M} \mathrm{KOH}$ solution $(\mathrm{pH} \sim 13)$ at $1.23 \mathrm{~V}$ vs RHE under the 1 Sun AM1.5G condition. Adapted with permission. ${ }^{[18]}$ @ 2017 American Chemical Society. 

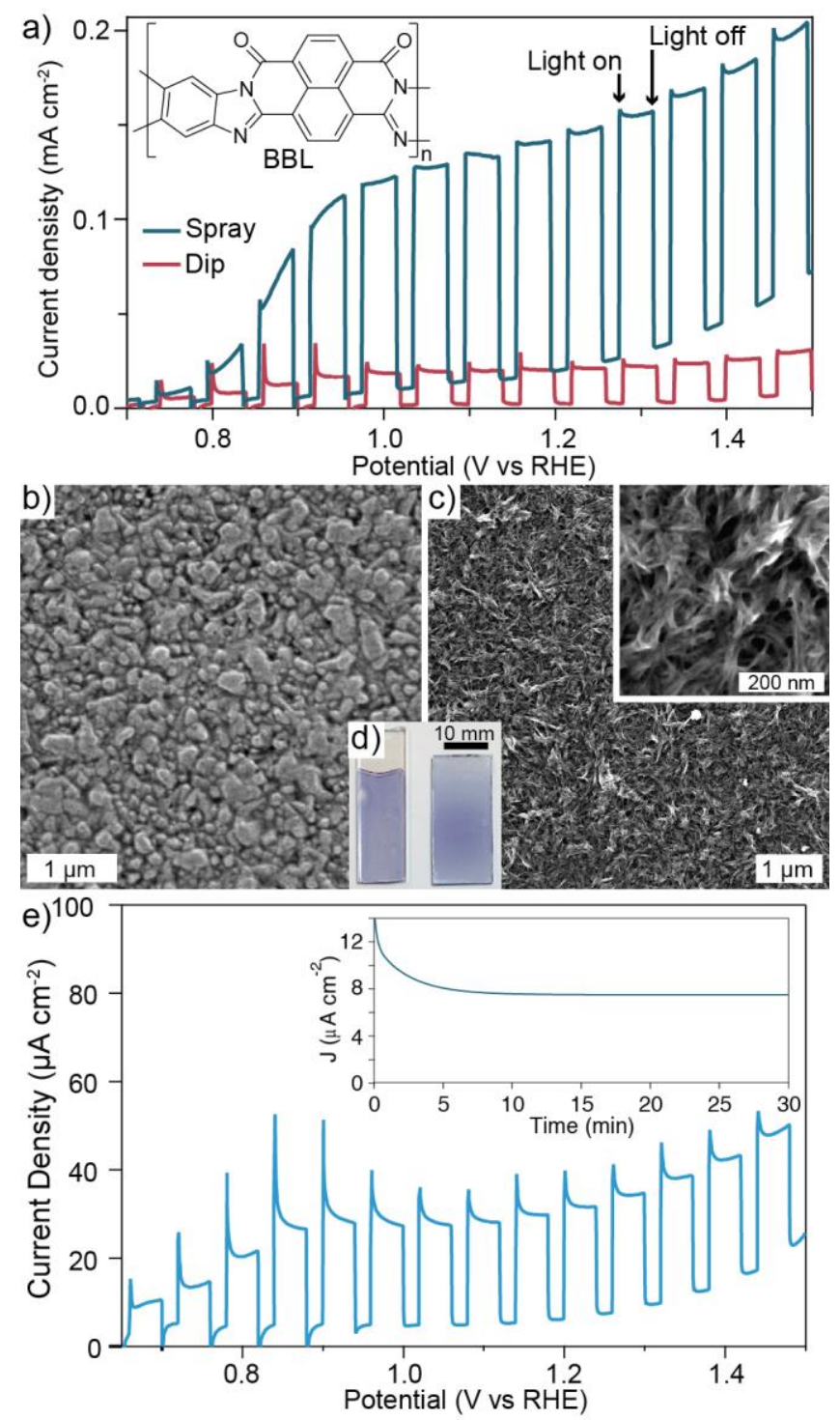

Figure 11. (a) The structure of BBL polymer and the J-V curve of a sprayed film (blue line) and a dip coated film (red line) in sacrificial electrolyte $\left(0.5 \mathrm{M} \mathrm{Na}_{2} \mathrm{SO}_{3}, \mathrm{pH}\right.$ 7) under chopped light substrate-side illumination (scan rate $10 \mathrm{mV} \mathrm{s}^{-1}$ ). Scanning electron micrographs (top view) of a dip-coated film (b) and sprayed film (c) with optical images of both electrodes (d). (e) The J-V curve in aqueous sulfate/phosphate electrolyte ( $\mathrm{pH} 7$ ) under chopped illumination. The inset shows the CA measurement at $1.23 \mathrm{~V}$ vs RHE. Adapted under the terms of the Standard ACS AuthorsChoice license. ${ }^{[119]}$ 
Table 1. Summary of key reports of OPV-biased water splitting.

\begin{tabular}{|c|c|c|c|c|c|c|c|c|c|}
\hline Configuration & BHJs & BHJ composition & ICL composition & $\eta_{P V}{ }^{a)}[\%]$ & Catalysts & $\begin{array}{l}V_{\text {op }} \\
{[V]}\end{array}$ & Electrolyte & $\begin{array}{c}\eta_{\mathrm{stH}^{\mathrm{a}}} \\
{[\%]}\end{array}$ & Ref. \\
\hline Side-by-side & 6 & P3HT:PC 61 BM & -- & 1.1 & $\left.P t^{b}\right), \mathrm{Pt}^{\mathrm{c})}$ & 2.6 & $0.1 \mathrm{M} \mathrm{H}_{2} \mathrm{SO}_{4}$ & 1.6 & [40] \\
\hline Tandem & 3 & $\begin{array}{l}\text { (1x)PF10TBT:PC }{ }_{61} \mathrm{BM} \\
\text { (2x)PDPPTPT:PC }{ }_{61} \mathrm{BM}\end{array}$ & $\begin{array}{c}\text { ZnO/pH neutral } \\
\text { PEDOT:PSS/Nafion }\end{array}$ & 5.3 & $P t^{b)}, P^{c)}$ & 1.7 & $1.0 \mathrm{M} \mathrm{KOH}$ & 3.1 & [64] \\
\hline Tandem & 2 & PTPTIBDT-OD :PC ${ }_{71} B M$ & $\begin{array}{c}\text { ZnO/pH neutral } \\
\text { PEDOT:PSS/MoO }\end{array}$ & 5.3 & $\begin{array}{l}\mathrm{RuO}_{2}^{\mathrm{b})} \\
\mathrm{RuO}_{2}{ }^{\mathrm{c})}\end{array}$ & 1.5 & $1.0 \mathrm{M} \mathrm{KOH}$ & 4.3 & [68] \\
\hline Tandem & 3 & $\begin{array}{l}\text { (1x)PCDTBT }{ }^{\mathrm{d})}: \mathrm{PC}_{71} \mathrm{BM} \\
(2 \mathrm{X}) \mathrm{PMDPP}^{\mathrm{e}} \mathrm{T}^{\mathrm{e}}: \mathrm{PC}_{61} \mathrm{BM}\end{array}$ & $\begin{array}{l}\text { ZnO/pH neutral } \\
\text { PEDOT:PSS }\end{array}$ & 6.7 & $\begin{array}{l}\mathrm{RuO}_{2}^{\mathrm{b})} \\
\mathrm{RuO}_{2}{ }^{\mathrm{c}}\end{array}$ & 1.5 & $1.0 \mathrm{M} \mathrm{KOH}$ & 5.4 & [65] \\
\hline Tandem & 3 & PTB7:PC ${ }_{71} \mathrm{BM}$ & $\mathrm{MoO}_{3} / \mathrm{Ag} / \mathrm{PFN}^{\mathrm{f}}$ & 8.7 & $\begin{array}{l}\mathrm{NiMoZn}{ }^{\mathrm{b})} \\
\mathrm{GC}^{\mathrm{Ru}} \mathrm{RuO}_{2}^{\mathrm{c}}\end{array}$ & 1.7 & $\begin{array}{c}0.1 \mathrm{M} \\
\text { phosphate } \\
\text { buffer, pH } \\
7.0\end{array}$ & 6.0 & [69] \\
\hline Side-by-side & 3 & PTB7-Th:PC ${ }_{71}$ BM & -- & 8.7 & $\begin{array}{l}\mathrm{Pt}^{\mathrm{b})} \\
\mathrm{RuO}_{2}{ }^{\mathrm{c})}\end{array}$ & 1.5 & $1.0 \mathrm{M} \mathrm{KOH}$ & 6.1 & [60] \\
\hline Tandem & 2 & PBDTTPD:PC ${ }_{71} \mathrm{BM}$ & $\mathrm{ZnO} / \mathrm{Al} / \mathrm{MoO}_{3}$ & 8.4 & $\begin{array}{l}\mathrm{Pt}^{\mathrm{b})}, \mathrm{Ni} \\
\text { foam }^{\mathrm{c}}\end{array}$ & 1.5 & $1.0 \mathrm{M} \mathrm{NaOH}$ & 6.1 & [67] \\
\hline $\begin{array}{l}\text { a) under } \\
9 \text { H-car } \\
\text { e) poly[ } \\
{ }^{\left[3^{\prime}, 3^{\prime \prime}-c\right.} \\
\text { dimeth }\end{array}$ & $\begin{array}{l}\text { imul } \\
\text { azole } \\
\text {,5-bi } \\
\text { meth }\end{array}$ & $\begin{array}{l}\text { ed 1-sun illuminati } \\
\text {,-diyl]-2,5-thioph } \\
\text { 2-hexyldecyl)-2,3,5 } \\
\text {-2,2':5',2'"-terthiop } \\
\text { propyl)-2,7-fluore }\end{array}$ & $\begin{array}{l}\text {; b) HER cataly } \\
\text { hediyl-2,1,3-be } \\
\text { 5-tetrahydro-3, } \\
\text { ne]-5,5"'-diyl]; } \\
\text {-alt-2,7-(9,9-c }\end{array}$ & $\begin{array}{l}{ }^{\mathrm{c})} \text { OER } \\
\text { thiadi } \\
\text { lioxop } \\
\text { oly[(9 } \\
\text { ctylflu }\end{array}$ & $\begin{array}{l}\text { talyst; } \\
\text { le-4,7-c } \\
\text { olo[3,4- } \\
\text { bis( } 3^{\prime}-(1 \\
\text { ne })]\end{array}$ & $\begin{array}{l}1-2 \\
\text { y- } \\
\text { J- }\end{array}$ & $\begin{array}{l}\text {-(1-octyli } \\
\text {-thiophen } \\
\text { le-1,4-diy }\end{array}$ & $\begin{array}{l}\text { nyl)- } \\
\text { iyl]; } \\
\text { alt- }\end{array}$ & \\
\hline
\end{tabular}


Table 2. Summary of organic semiconductor photoelectrodes for solar water splitting.

\begin{tabular}{|c|c|c|c|c|c|c|c|}
\hline $\begin{array}{l}\text { Photoelectrode } \\
\text { type }\end{array}$ & $\begin{array}{l}\text { Photoactive } \\
\text { layer }\end{array}$ & $\mathrm{HTL}^{\text {a) }}$ & $E T L^{b)}$ & Catalyst $^{c)}$ & $J_{p h}{ }^{d)}$ & Electrolyte & Ref. \\
\hline Photocathode & $\mathrm{P} 3 \mathrm{HT}: \mathrm{PC}_{61} \mathrm{BM}$ & -- & -- & -- & $<1 \mu \mathrm{A} \mathrm{cm}^{-2}$ & $0.2 \mathrm{M} \mathrm{NaCl}$ & [94] \\
\hline Photocathode & BDT-ETTA COF & -- & -- & $\begin{array}{c}\mathrm{Pt} \\
\text { nanoparticles }\end{array}$ & $\begin{array}{c}\sim 10 \mu \mathrm{A} \mathrm{cm} \mathrm{cm}^{-2} @ 0 \\
\mathrm{~V} \text { vs RHE }\end{array}$ & $0.1 \mathrm{M} \mathrm{Na}_{2} \mathrm{SO}_{4}$ & {$[90]$} \\
\hline Photocathode & PTBh & -- & -- & -- & $\begin{array}{c}0.11 \mathrm{~V} \text { vs } \mathrm{RHE} \\
\text { (1.6 suns) }\end{array}$ & $\begin{array}{c}1 \mathrm{M} \text { phosphate buffer } \\
(\mathrm{pH} 7)\end{array}$ & [80] \\
\hline Photocathode & PTTh & -- & -- & -- & $\begin{array}{c}\sim 120 \mu \mathrm{A} \mathrm{cm}{ }^{-2} @ \\
\text { 0 V vs RHE }\end{array}$ & $\begin{array}{l}1 \mathrm{M} \text { phosphate buffer } \\
\text { Adj. w/ } \mathrm{NaOH}(\mathrm{pH} 11)\end{array}$ & [81] \\
\hline Photocathode & $\mathrm{P} 3 \mathrm{HT}: \mathrm{PC}_{61} \mathrm{BM}$ & PEDOT:PSS & $\mathrm{TiO}_{2}$ & $\mathrm{MoS}_{3}$ & $\begin{array}{c}200 \mu \mathrm{A} \mathrm{cm} \mathrm{cm}^{-2} @ 0 \\
\text { V vs RHE }\end{array}$ & $0.5 \mathrm{M} \mathrm{H}_{2} \mathrm{SO}_{4}$ & [95] \\
\hline Photocathode & $\mathrm{P} 3 \mathrm{HT}: \mathrm{PC}_{61} \mathrm{BM}$ & $\begin{array}{l}\text { Cross-linked } \\
\text { PEDOT:PSS }\end{array}$ & AZO & $\mathrm{Pt}$ & $\begin{array}{c}1.2 \mathrm{~mA} \mathrm{~cm}^{-2} @ 0 \\
\text { V vs RHE }\end{array}$ & $\begin{array}{l}0.2 \mathrm{M} \mathrm{KCl} \text { in phosphate } \\
\text { buffer (pH 6.9) }\end{array}$ & {$[104]$} \\
\hline Photocathode & P3HT:PC 61 BM & $\mathrm{MoS}_{2}$ & $\mathrm{TiO}_{2}$ & $\mathrm{MoS}_{3}$ & $\begin{array}{c}1.21 \mathrm{~mA} \mathrm{~cm}^{-2} @ 0 \\
\text { V vs RHE }\end{array}$ & $0.5 \mathrm{M} \mathrm{H}_{2} \mathrm{SO}_{4}$ & [101] \\
\hline Photocathode & $\mathrm{P} 3 \mathrm{HT}: \mathrm{PC}_{61} \mathrm{BM}$ & $\mathrm{MoO}_{x}$ & -- & $\mathrm{MoS}_{3}$ & $\begin{array}{c}2.2 \mathrm{~mA} \mathrm{~cm}^{-2} @ 0 \\
\text { V vs RHE }\end{array}$ & $0.5 \mathrm{M} \mathrm{H}_{2} \mathrm{SO}_{4}$ & [99] \\
\hline Photocathode & P3HT:PC 61 BM & $\begin{array}{c}\text { Cross- } \\
\text { linkable } \\
\text { PEDOT:PSS }\end{array}$ & $\mathrm{TiO}_{x}$ & $\mathrm{Pt}$ & $\begin{array}{l}\sim 3 \mathrm{~mA} \mathrm{~cm}{ }^{-2} @- \\
0.10 \mathrm{~V} \text { vs RHE }\end{array}$ & $\begin{array}{c}0.1 \mathrm{M} \mathrm{Na}_{2} \mathrm{SO}_{4} \mathrm{Adj} . \mathrm{w} / \\
\mathrm{H}_{2} \mathrm{SO}_{4}(\mathrm{pH} 2)\end{array}$ & {$[100]$} \\
\hline Photocathode & P3HT:PC ${ }_{61} B M$ & $\mathrm{MoO}_{3}$ & $\mathrm{TiO}_{2}$ & $\mathrm{Pt}$ & $\begin{array}{c}\sim 3 \mathrm{~mA} \mathrm{~cm}^{-2} @ 0 \\
\text { V vs RHE }\end{array}$ & $\begin{array}{l}0.1 \mathrm{M} \mathrm{H} \text { HSO4 Adj. w/ } \\
\mathrm{Na}_{2} \mathrm{SO}_{4}(\mathrm{pH} 1.4)\end{array}$ & [103] \\
\hline Photocathode & $\mathrm{P} 3 \mathrm{HT}: \mathrm{PC}_{61} \mathrm{BM}$ & Cul & $\mathrm{TiO}_{2}$ & $\mathrm{RuO}_{\mathrm{x}}$ & $\begin{array}{l}\sim 3.7 \mathrm{~mA} \mathrm{~cm}^{-2} @ \\
0 \mathrm{~V} \text { vs RHE }\end{array}$ & $\begin{array}{c}0.5 \mathrm{M} \mathrm{Na}_{2} \mathrm{SO}_{4}+0.1 \mathrm{M} \\
\mathrm{NaH}_{2} \mathrm{PO}_{4}(\mathrm{pH} 5)\end{array}$ & [102] \\
\hline Photocathode & P3HT:PC ${ }_{61} B M$ & GO & $\mathrm{TiO}_{2}$ & Pt/C-Nafion & $\begin{array}{c}6.01 \mathrm{~mA} \mathrm{~cm}^{-2} @ 0 \\
\text { V vs RHE }\end{array}$ & $0.5 \mathrm{M} \mathrm{H}_{2} \mathrm{SO}_{4}$ & [112] \\
\hline Photocathode & $\mathrm{P} 3 \mathrm{HT}: \mathrm{PC}_{61} \mathrm{BM}$ & Cul & $\mathrm{TiO}_{2}$ & $\mathrm{Pt}$ & $\begin{array}{c}5.25 \mathrm{~mA} \mathrm{~cm}^{-2} @ 0 \\
\text { V vs RHE }\end{array}$ & $\begin{array}{c}0.1 \mathrm{M} \mathrm{H}_{2} \mathrm{SO}_{4}-\mathrm{Na}_{2} \mathrm{SO}_{4} \\
(\mathrm{pH} \mathrm{1})\end{array}$ & [111] \\
\hline Photocathode & P3HT:PC 61 BM & Cul & $\mathrm{TiO}_{2}$ & $\mathrm{Pt}$ & $\begin{array}{c}7.1 \mathrm{~mA} \mathrm{~cm} \mathrm{~cm}^{-2} @ 0 \\
\text { V vs RHE }\end{array}$ & $\begin{array}{c}0.1 \mathrm{M} \mathrm{H}_{2} \mathrm{SO}_{4}+0.1 \mathrm{M} \\
\mathrm{Na}_{2} \mathrm{SO}_{4}(\mathrm{pH} 1)\end{array}$ & {$[107]$} \\
\hline Photocathode & P3HT:PC 61 BM & PEDOT:PSS & $\begin{array}{c}\mathrm{LiF} / \mathrm{Al} / \\
\mathrm{Ti}\end{array}$ & $\mathrm{MoS}_{3}$ & $\begin{array}{c}8.4 \mathrm{~mA} \mathrm{~cm}^{-2} @ 0 \\
\text { V vs RHE }\end{array}$ & $0.5 \mathrm{M} \mathrm{H}_{2} \mathrm{SO}_{4}$ & [105] \\
\hline Photoanode & PTCBI & -- & -- & $\mathrm{CoPc}$ & $\begin{array}{c}\sim 20 \mu \mathrm{A} \mathrm{cm} \mathrm{cm}^{-2} @ \\
1.2 \mathrm{~V} \text { vs RHE }\end{array}$ & $1 \mathrm{mM} \mathrm{NaOH}(\mathrm{pH} 11)$ & [115] \\
\hline Photoanode & $\mathrm{BBL}$ & -- & -- & $\mathrm{Ni}-\mathrm{Co}$ & $\begin{array}{l}\sim 30 \mu \mathrm{A} \mathrm{cm} \mathrm{cm}^{-2} @ \\
1.23 \mathrm{~V} \text { vs RHE }\end{array}$ & $\begin{array}{c}0.6 \mathrm{M} \text { sulfate/phosphate } \\
\text { buffer }(\mathrm{pH} 7)\end{array}$ & {$[119]$} \\
\hline Photoanode & $\mathrm{PC}_{71} \mathrm{BM}$ & $\mathrm{ZnO}$ & $\mathrm{ZnO}$ & -- & $\begin{array}{l}\sim 60 \mu \mathrm{A} \mathrm{cm} \mathrm{cm}^{-2} @ \\
1.23 \mathrm{~V} \text { vs RHE }\end{array}$ & $0.1 \mathrm{M} \mathrm{KOH}(\mathrm{pH} \mathrm{13)}$ & [118] \\
\hline Photoanode & PTCDA: $\mathrm{PC}_{61} \mathrm{BM}$ & -- & -- & -- & $\begin{array}{c}\sim 100 \mu \mathrm{A} \mathrm{cm}^{-2} @ \\
1.2 \mathrm{~V} \text { vs RHE }\end{array}$ & $\begin{array}{c}35 \mathrm{mM} \mathrm{KNO}_{3} \text { Adj. w/ } \\
\mathrm{H}_{2} \mathrm{SO}_{4}(\mathrm{pH} 2)\end{array}$ & {$[116]$} \\
\hline Photoanode & PMPDI & -- & -- & $\mathrm{CoO}_{x}$ & $\begin{array}{c}\sim 150 \mu \mathrm{A} \mathrm{cm} \mathrm{cm}^{-2} @ \\
1.56 \mathrm{~V} \text { vs RHE }\end{array}$ & $0.1 \mathrm{M} \mathrm{KPi}$ buffer $(\mathrm{pH} 7)$ & [117] \\
\hline
\end{tabular}

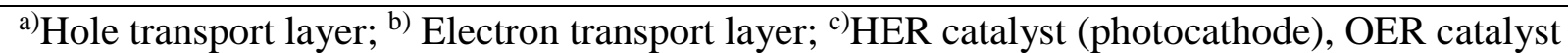

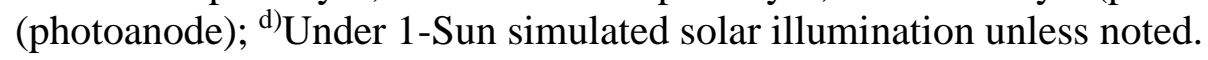


